يشيبنى تغييرات تراز آب زيرزمينى با استفاده از مدل تركيبى موجك- ماشين آموزش نيرومند خودتطبيقى - جاه مشاهداتى سراب قنبر كرمانشاه

فريبرز يوسفوند و وسعيد شعبانلو'

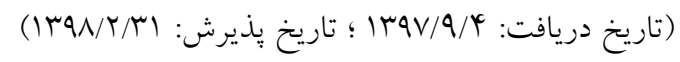

جكيده

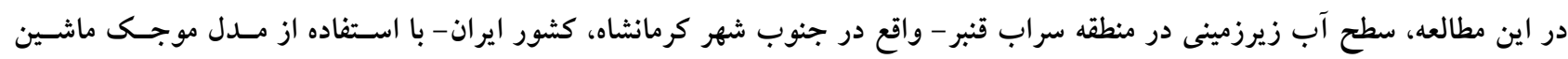

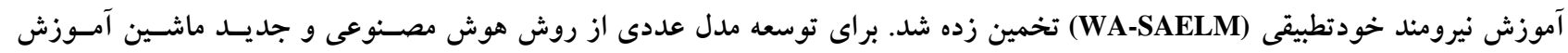

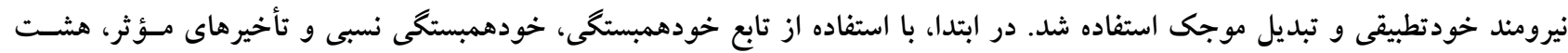

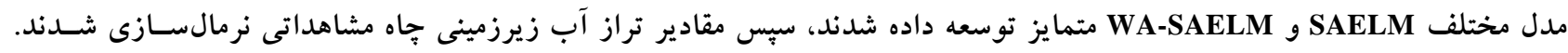

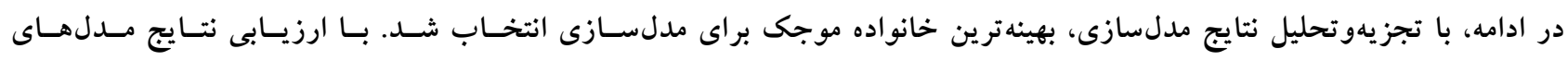

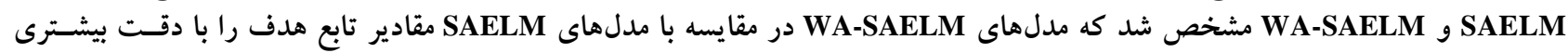

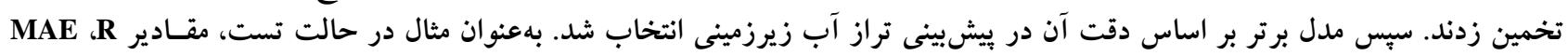

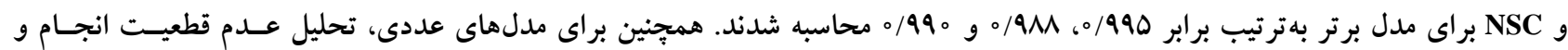

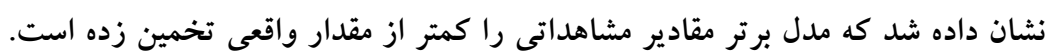

وازههاى كليدى: تراز آب زيرزمينى، ماشين آموزش نيرومند خودتطبيقى، تحليل عدم قطعيت، تبديل موجى 
ديتاهاى كافى هستند مناسب بود. عـلاوه بــر ايسن، ملكعزاده و

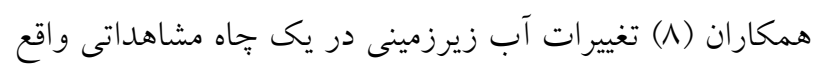

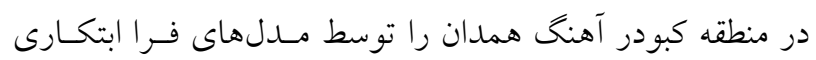

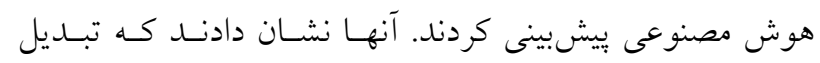
موجك توانايى مدلسازى را به شكل قابل توجهى افزايش داد. با بررسى مطالعات كذشـته مشـاهده مسى شـود كـه تـاكنون

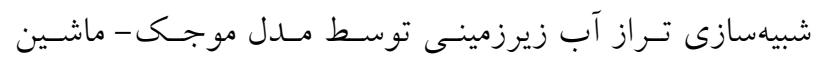

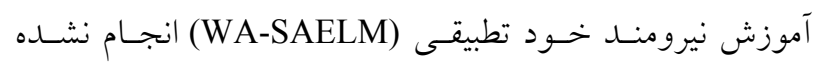

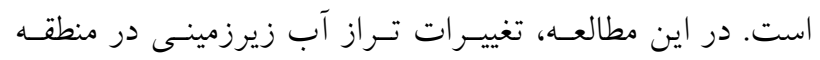

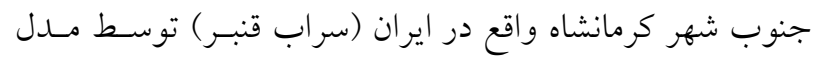

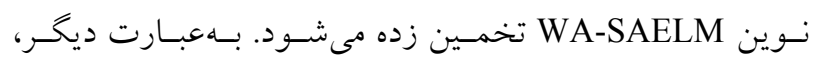

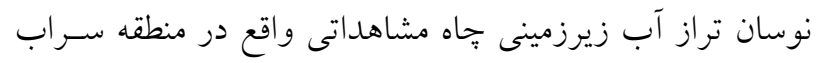

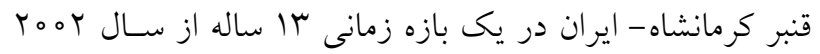

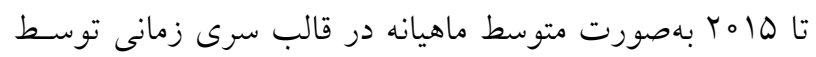
مدل بسيار قدرتمند WA-SAELM مدلسازى مىشود.

\section{مواد و روشها - - ماد}

در بخش مواد و روشها، ابتدا ناحيه مورد مطالعه مورد بررسى

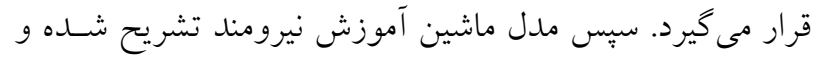

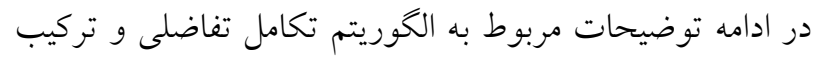

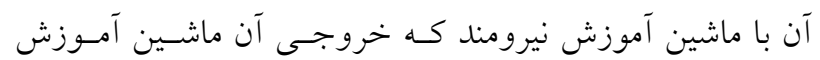

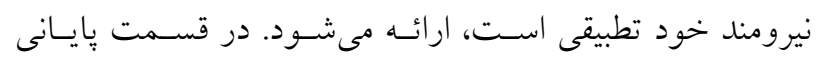

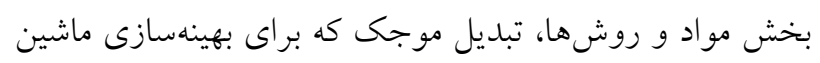

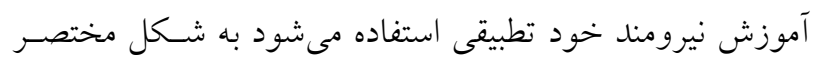

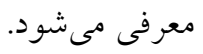

ناحيه مورد مطالعه منطقه مطالعاتى در اين مطالعه در منطقه سراب قنبـر در جنـوب مورد

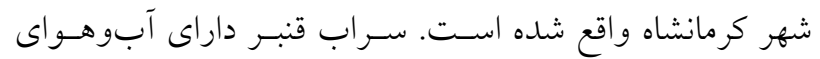

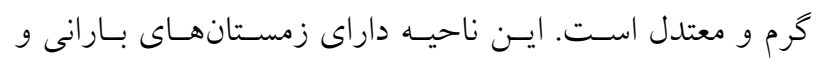
تابستانهاى خنكى است. در اين منطقه ميـانخين سـالانه دمـا در

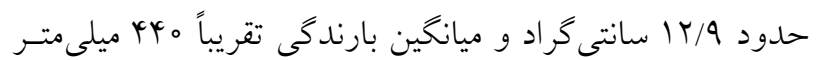

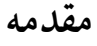

آبهاى زيرزمينى يكى از منابع آب شرب محسوب مسىشـوند.

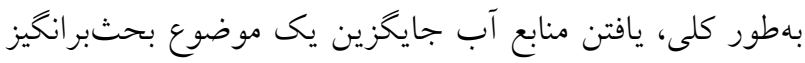

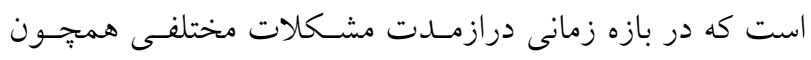

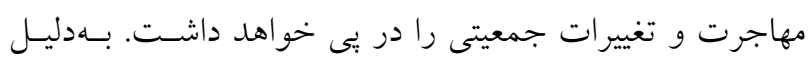

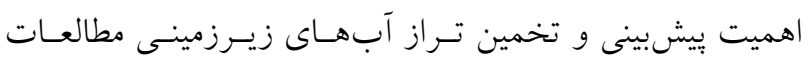

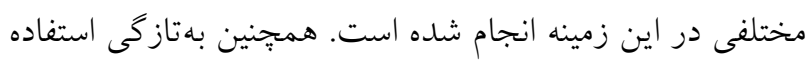

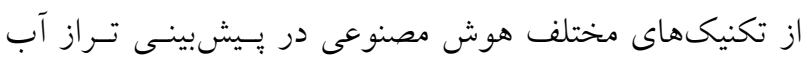

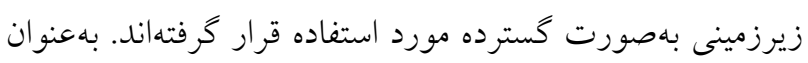

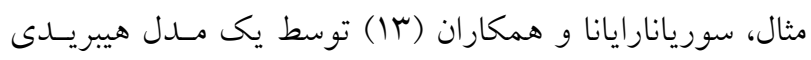

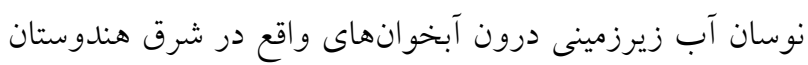

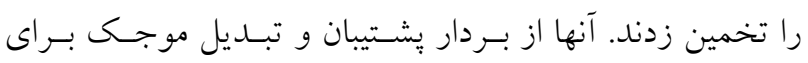
توسعه مدل هيبريدى مذكور استفاده كردند و مقادير ايسن روش را با شبكه عصبى مصنوعى مقايسه كردنـــ. خـاكى و همكــاران

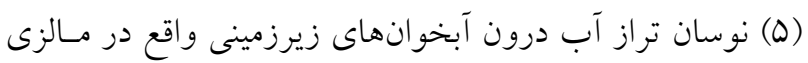

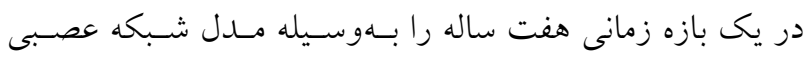

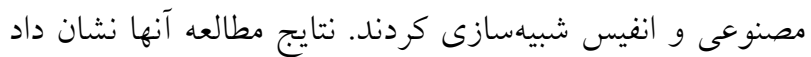

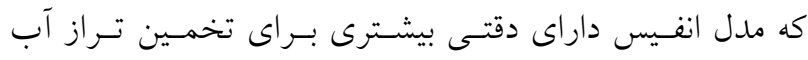

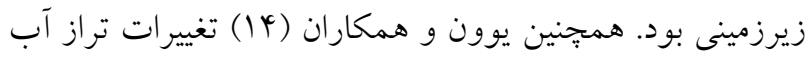

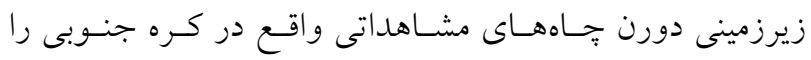

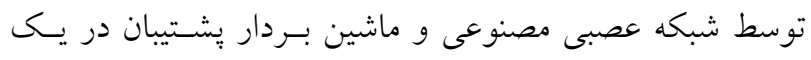

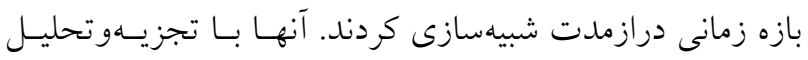

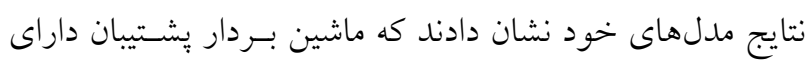

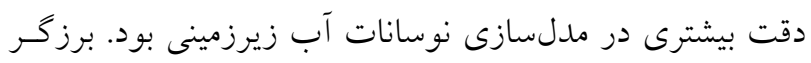

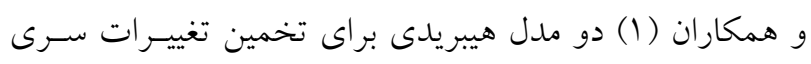

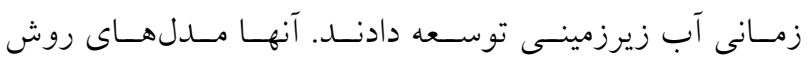

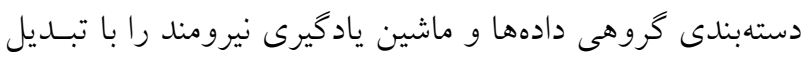

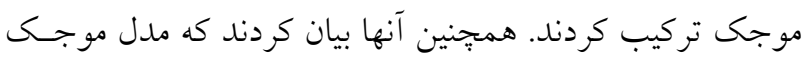

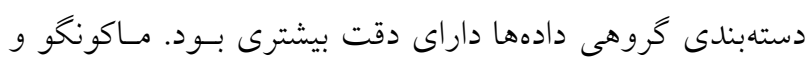

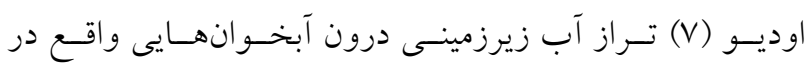

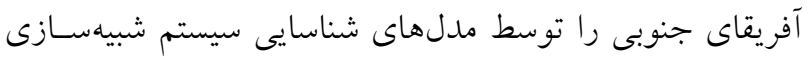

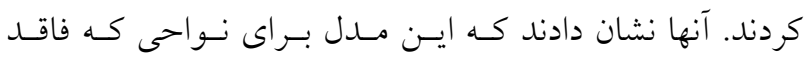


كه عمدتاً كارستيك بوده خـود باعـث تغذيسه آبخــوان ميشـود.

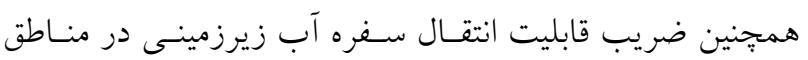

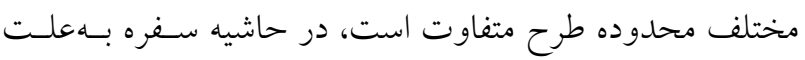

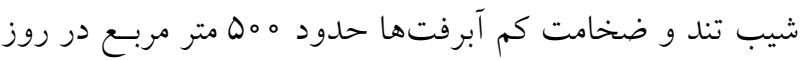

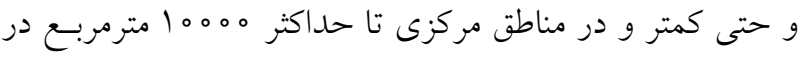
روز متغير است.

مقادير مشاهداتى در يك بازه زمانى سا ساله از سـال roor تا ها ب ب بهصورت متوسط ماهيانه استفاده شدند. تغييرات سطح آب زيرزمينس و همجنـين ميـزان بارنسـى ماهيانه در اين ناحيه براى سا سال آبى بررسى شده كه بر اساس نتايج مشخص شد كه روند سطح آب در دشـت در ايسن بـازه زمانى سير نزولى داشته به كونهاى كه طى ايـن سا سـال حسدود

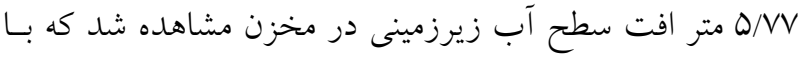

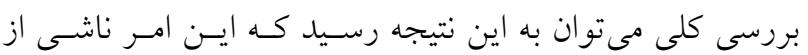

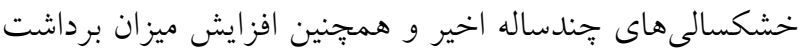

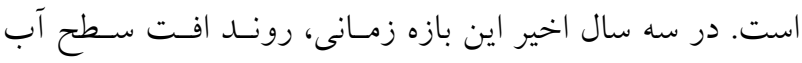

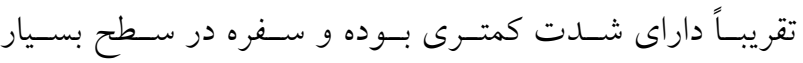
پايين ترى نسبت به سالهاى قبل به تعادل نسبى رسيد. بهعبارت ديخر تعداد مقادير برداشـت شــده بـراى 109 مـاه متوالى در قالب سرى زمانى استفاده شدند. علاوه بر اين، 9 سال

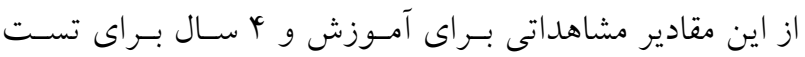

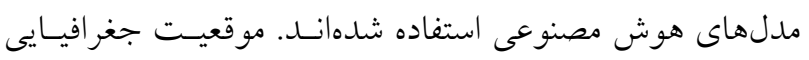
جاه سراب قنبر در شكل (1) به تصوير كشيده شده است.

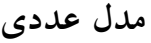

ماشين آموزش نيرومند (Extreme Learning Machine)

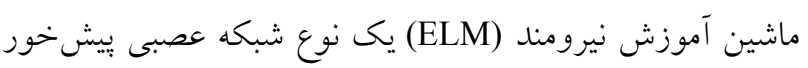
r) تكىلايه است كه توسط هو انخ و همكاران (Feed-forward)

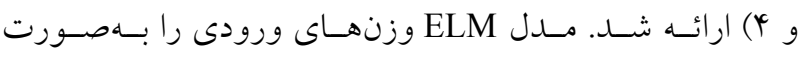

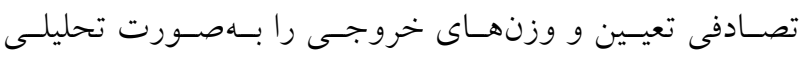
تعيين مى كند. تنها تفاوت ELM (Analytical)

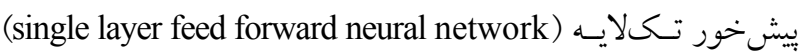

اسـت. مختصـات جغر افيـايى منطقـه مـذكور MY/YNV0 درجسه شمالى و FV/ODFV درجه شـرقى اسـت. در ايـن مطالعـه بـراى

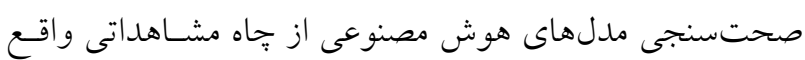
در اين منطقه استفاده شد. سرتاسر حاشيه شمالى و شرقى و قسمتى از حاشـيه شـمال

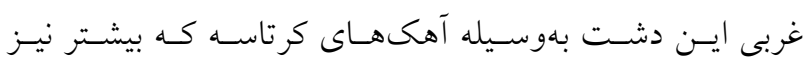

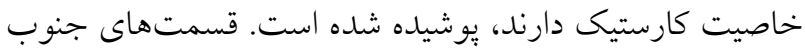
و جنوب شرقى و در بخشى از شمال غربى به ارتفاعاتى محدود

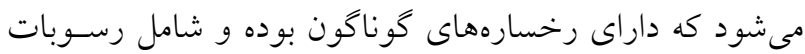

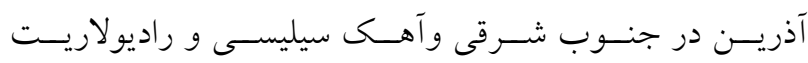

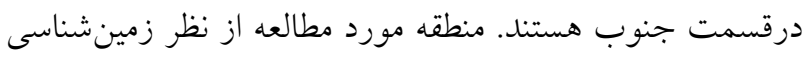
جزء دو ساختار زون زاگرس و زون خرد شــده اسـت. ايـن دو بخش بههمراه دشت خوزستان تمامى ساختار زاكرس را تشكيل

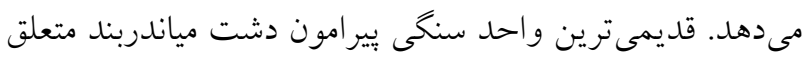

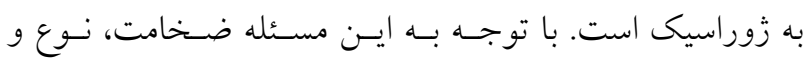
دانهبندى آبرفت در اين دشت در نقاط مختلف متفـاوت اسـت

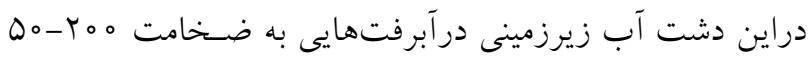

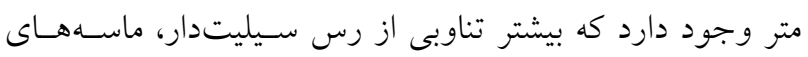
ريز و درشت و ريخ هستـند. بـهنور كلى كوهيايسه و حاشسيه

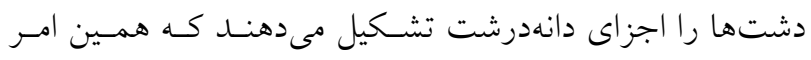

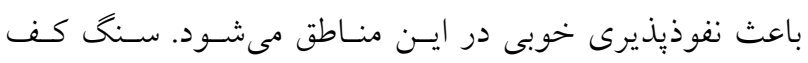

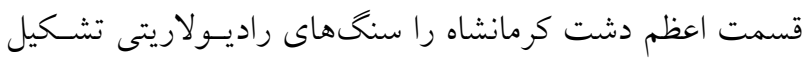

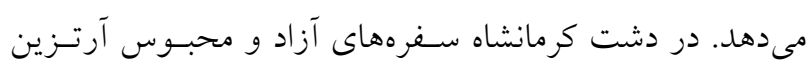

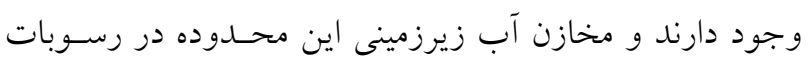

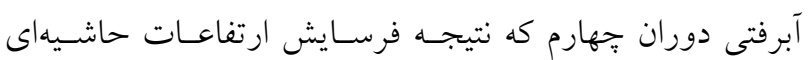

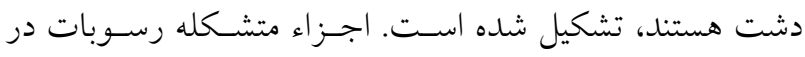

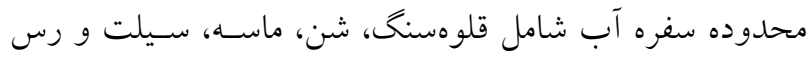

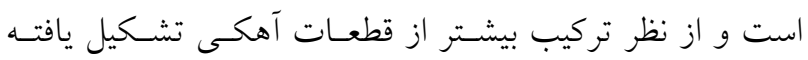

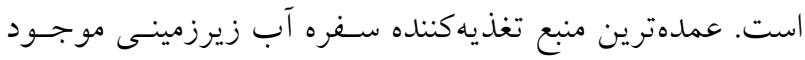

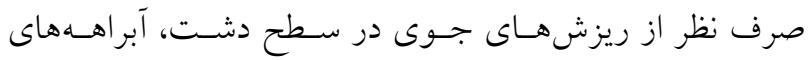
متعددى هستند كه از دامنه ارتفاعات مجاور سرجشمه كرفتسه و وارد محدوده دشت مىشوند، همجنين وجود جِشمهاى فراوان 
استفاده مىشود. رفتار نرونها از دو بخش تشكيل شده است كه

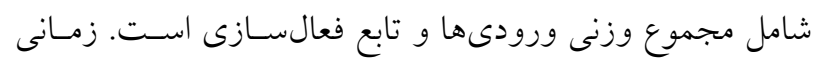

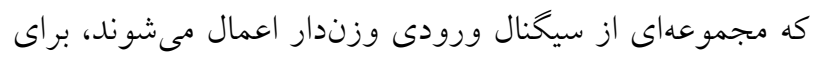

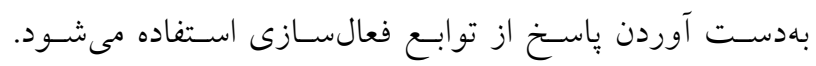

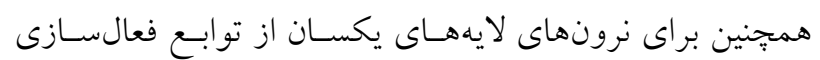

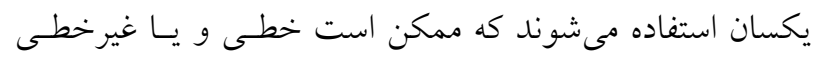

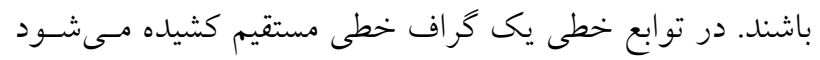

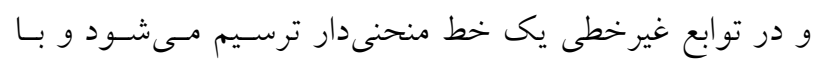

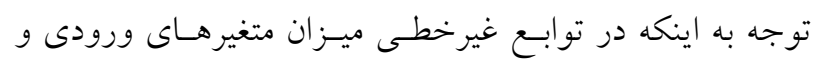
خروجى ثابت نيستند مشكلات طبقهبندى در آنها معمول است.

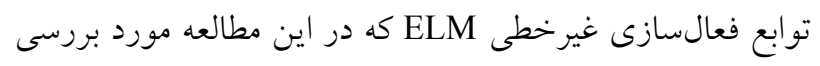

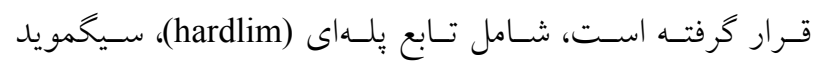

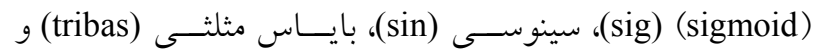

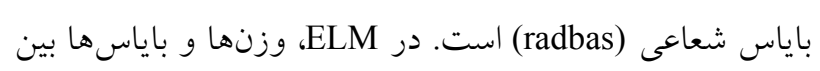

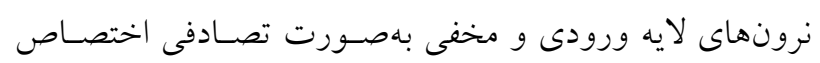

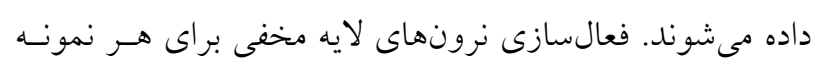

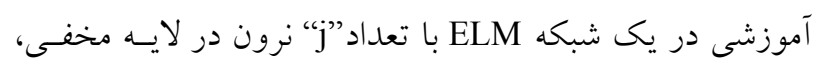

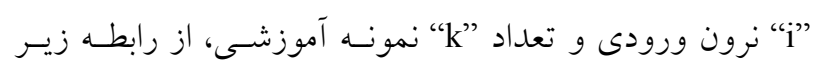

$\mathrm{H}_{\mathrm{jk}}=\mathrm{g}\left(\sum \mathrm{W}_{\mathrm{ji}} \mathrm{X}_{\mathrm{ik}}\right)+\mathrm{B}_{\mathrm{j}}$

كه در اينجا (.) مى تواند هر تابع فعالسازى غيرخطى بيوسته

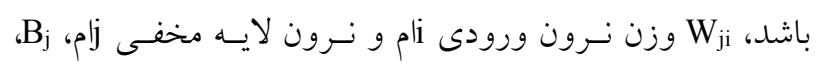

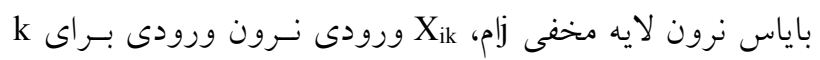

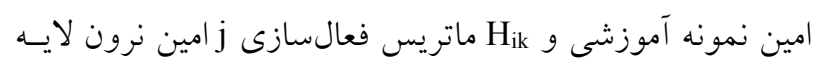

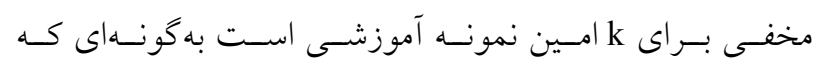

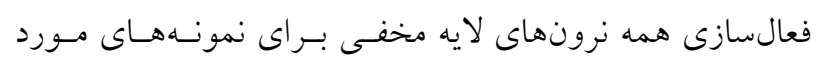

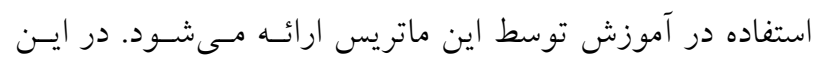

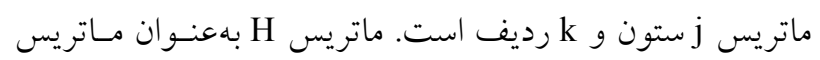

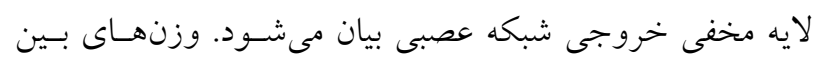

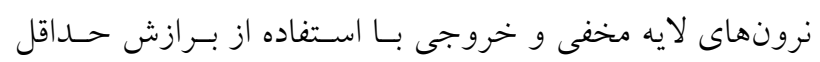

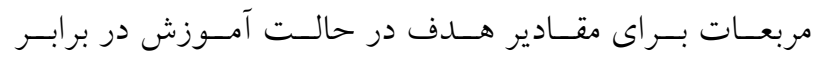

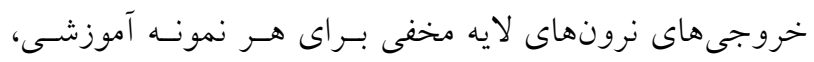

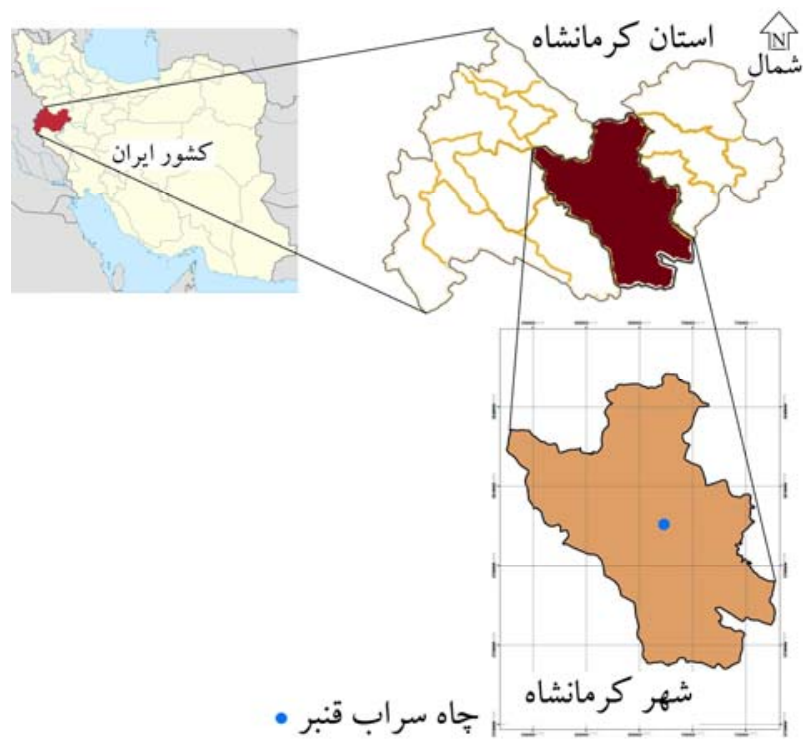

شكل 1. موقعيت جغرافيايى خاه مورد مطالعه

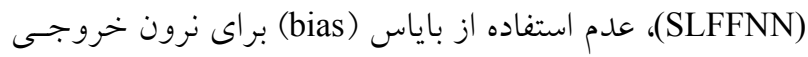

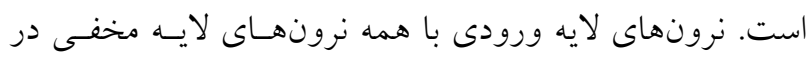

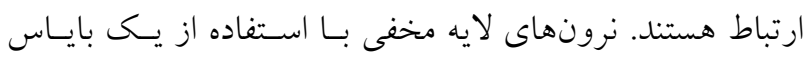

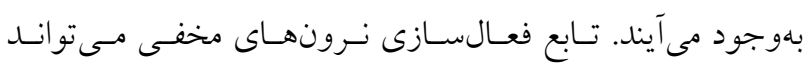
بهورت تابع ييوسته تكـهاى (piecewise continuous function) باشد درحالى كه براى نرون لايه خروجى بهصورت خطى است.

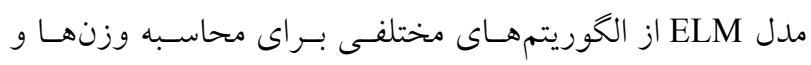

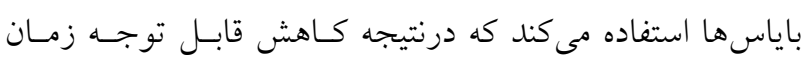

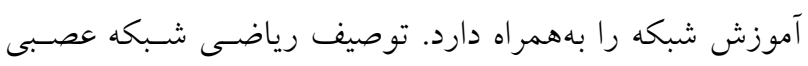

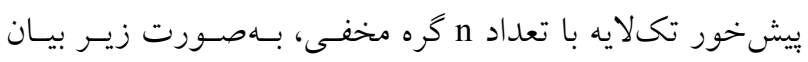

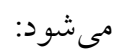
$f_{n}(x)=\sum_{i=1}^{n} \beta_{i} G\left(a_{i}, b_{i}, x\right)$

كه

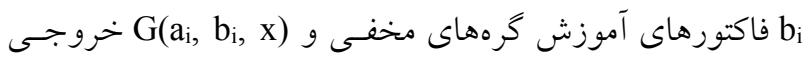

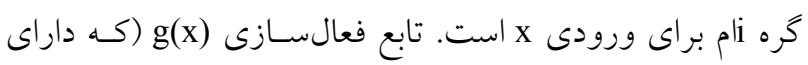

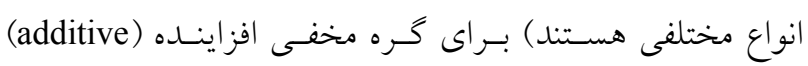

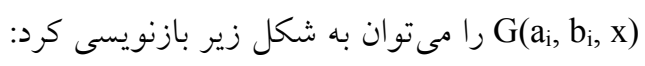
$\mathrm{G}\left(\mathrm{a}_{\mathrm{i}}, \mathrm{b}_{\mathrm{i}}, \mathrm{x}\right)=\mathrm{g}\left(\mathrm{a}_{\mathrm{i}} \cdot \mathrm{x}+\mathrm{b}_{\mathrm{i}}\right)$ از توابع فعالسازى بهمنظور محاسبه خروجسى بِاسـخ نـرونهـا 
فضاى ورودى تصافى غيرخطى كار مى كنــــ بـهـــورى كـه هـر نرون با يك نمونه تصادفى منفرد در ارتباط است.

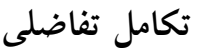

روش بهينهسازى تكامـل تفاضـلى (DE) يكسى از تكنيـكهـاى نسبتاً جديد در زمينه بهينهسـازى فراكاوشسى اسـت كـه توسـط استورن و يرايس (T) ارائـهـ شــه اسـت. در سـالهــاى اخيـر الكوريتم تكامل تفاضلى بهعنوان روشى قدرتمند و سريع بـراى مسائل بهينهسـازى در فضـاهاى بيوسـته معرفى شـــه اسـت و توانايى خوبى در بهينهسازى توابع غيرخطى مشـتقنإِــير دارد.

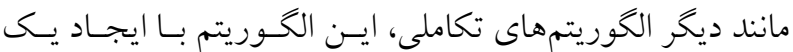

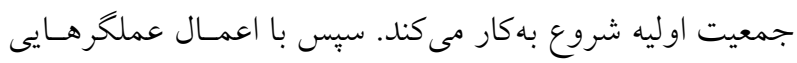
شامل تركيب، جهش و تقاطع، نسـل فرزنــ تشـكيل شــده و در

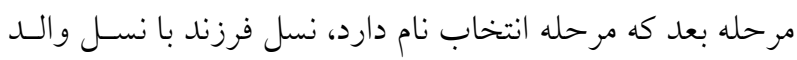
براى ميزان شايستخى كه توسط تابع هدف سنجيده مىشود، مقايسه مىشود. سيس بهترين اعضا بهعنوان نسل بعلى وارد مرحلـه بعـــ مىشوند. اين عمل تا رسيدن به نتايج مطلوب ادامه مىيابد.

\section{ماشين آموزش نيرومند خود تطبيقى} در اين مطالعه، براى بهينههازى ماشين آمسوزش نيرومنـد از الكوريتم تكامل تفاضـلى بهـره كرفتـه مى شـود. اسـتفاده از الكوريتم تكامل تفاضلى بهصورت خودتطبيقى توانايى غلبه بـر محسـدوديتهــاى موجــود ماننـــ يار امترهــاى كنتـرل در الخــوريتم و انتخــاب اســتراتزى بــــدار آمــوزش را دارد. بنابراين، الكُوريتم ماشـين آمـوزش نيرومنـد خــود تطبيقى بـراى بهينــهــازى وزنهـاى ورودى شـبكه و (SAELM) باياسهاى كره مخفى، توسـط كـائو و همكــاران (Y) ارائسه شد. با داشتن مجموعسه دادههـاى آموزشسى، تعـداد L كـــه مخفى و تابع فعالسازى (x)، مئوتوان الخـوريتم SAELM را فرمولنويسى كرد. بدين منظور، ابتـدا جمعيست اوليسه بـا استفاده از بردارهاى جمعيت (NP) كه گـــهــاى مخفـى را دربر مى گيرند توليد مى شود. برداي
به كار برده مىشود كه معادل رياضى آن را مىتوان به شكل زيـر بيان نوشت:

$\mathrm{H} \beta=\mathrm{T}$

$\beta=\left(\beta_{1}, \ldots, \beta_{\mathrm{j}}\right)_{\mathrm{j} \times 1}$

كه $\beta$ نشاندهنده وزن بين نرون لايه خورجى و نرونهـاى لايسه مخفى است و T بردار نشاندهنده مقادير هدف براى نمونههاى آموزش بوده كه بهصورت زير بيان مىشود:

$\mathrm{T}=\left(\mathrm{T}_{1}, \ldots, \mathrm{T}_{\mathrm{k}}\right)_{\mathrm{k} \times 1}$ درنهايت وزنها را مىتوان از رابطه زير محاسبه كرد: $\beta=\mathrm{H}^{\prime} \mathrm{T}$

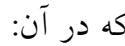
$H(\tilde{a}, \tilde{b}, \tilde{x})=\left[\begin{array}{ccc}G\left(a_{1}, b_{1}, x_{1}\right) & \ldots & G\left(a_{L}, b_{L}, x_{L}\right) \\ G\left(a_{1}, b_{1}, x_{N}\right) & \ldots & G\left(a_{L}, b_{L}, x_{N}\right)\end{array}\right]_{N \times L}$

$\beta=\left[\begin{array}{c}\beta_{1}^{\mathrm{T}} \\ \vdots \\ \beta_{\mathrm{L}}^{\mathrm{T}}\end{array}\right]_{\mathrm{L} \times \mathrm{m}} \quad$ and $\quad \mathrm{T}=\left[\begin{array}{c}\mathrm{T}_{1}^{\mathrm{T}} \\ \vdots \\ \mathrm{T}_{\mathrm{L}}^{\mathrm{T}}\end{array}\right]_{\mathrm{L} \times \mathrm{m}}$

كـهـ بين نرونهاى لايه هاى مخفى و لايه ينهان و H' شـبه معكسوس مـاتريس H اسـت. مـاتريس T بـردار بـين وزنهاى نمونههاى آموزشى است. بـا توجـهـ بـهـ توضـيحات ارائه شده مى توان كفت كه آمـوزش ELM شـامل دو مرحلـه است: مرحله اول، اختصاص تصادفى وزنها و بايـاسهـا بـــ نرونهاى لايه ينهان و محاسبه خروجى لايه ينهان ماتريس H و مرحلـه دوم، محاسـبه وزنهــاى خروجـى بــا اسـتفاده از شبهمعكـوس Moore-Penrose مـاتريس H و مقـادير هـدف براى نمونههاى آموزشى مختلف هستند. روند آموزش بـراى ييدا كردن شبهمعكوس Moore-Pensore ماتريس لايه ينهـان (H)، سريع است بهصورتى كه از سرعت بـالاترى نسـبت بـه الكوريتمهاى مبتنى بر تكرار رايج مانند لونبرگ- ماركو آردت كــه در آن هــيج نـــــ روالــى از (Levenberg-Marquardt) بهينهسازى غيرخطى را دربر نمى گيرد، برخوردار است. بنسابراين زمان آموزش شبكه بهطور قابل توجهى كاهش مىيابد (هوآنـ، بأ). همجنين، مدل ELM با اسـتفاده از تعـاد زيـادى از بـيشبينى 
Model $r: G W L(t)=f(G W L(t-1), G W L(t-r))$

تبديل موجك

Model r: GWL $(\mathrm{t})=\mathrm{f}(\mathrm{GWL}(\mathrm{t}-1), \operatorname{GWL}(\mathrm{t}-\mathrm{r})$, $\operatorname{GWL}(\mathrm{t}-r))$

Model $\uparrow:$ GWL $(\mathrm{t})=\mathrm{f}(\mathrm{GWL}(\mathrm{t}-1), \mathrm{GWL}(\mathrm{t}-\mathrm{r})$, $\operatorname{GWL}(\mathrm{t}-\mathrm{r}), \operatorname{GWL}(\mathrm{t}-\mathrm{r}))$

Model $\diamond: \operatorname{GWL}(\mathrm{t})=\mathrm{f}(\mathrm{GWL}(\mathrm{t}-1), \operatorname{GWL}(\mathrm{t}-\mathrm{r})$, $\operatorname{GWL}(\mathrm{t}-\mathrm{r}), \operatorname{GWL}(\mathrm{t}-\mathrm{r}), \operatorname{GWL}(\mathrm{t}-\mathrm{a}))$

Model $9: \operatorname{GWL}(\mathrm{t})=\mathrm{f}(\mathrm{GWL}(\mathrm{t}-1), \operatorname{GWL}(\mathrm{t}-\mathrm{r})$, $\operatorname{GWL}(\mathrm{t}-r), \operatorname{GWL}(\mathrm{t}-\mathrm{r}), \operatorname{GWL}(\mathrm{t}-\Delta), \operatorname{GWL}(\mathrm{t}-q))$

Model $V: \operatorname{GWL}(\mathrm{t})=\mathrm{f}(\operatorname{GWL}(\mathrm{t}-1), \operatorname{GWL}(\mathrm{t}-\mathrm{r})$,

$\operatorname{GWL}(\mathrm{t}-r), \operatorname{GWL}(\mathrm{t}-\mathrm{r}), \operatorname{GWL}(\mathrm{t}-\boldsymbol{\omega})$, $\operatorname{GWL}(\mathrm{t}-\varphi), \operatorname{GWL}(\mathrm{t}-\mathrm{v}))$

Model $\wedge: \operatorname{GWL}(\mathrm{t})=\mathrm{f}(\operatorname{GWL}(\mathrm{t}-1), \operatorname{GWL}(\mathrm{t}-\mathrm{r})$,

$\operatorname{GWL}(\mathrm{t}-\mathrm{r}), \operatorname{GWL}(\mathrm{t}-\mathrm{r}), \operatorname{GWL}(\mathrm{t}-\boldsymbol{\omega})$,

$\operatorname{GWL}(\mathrm{t}-\varphi), \operatorname{GWL}(\mathrm{t}-\mathrm{v}), \operatorname{GWL}(\mathrm{t}-\wedge))$

\section{معيارهاى بررسى دقت مدلهاى عددى}

در مطالعه حاضر بهمنظور ارزيابى دقت مدلهاى عددى معرفى لـى

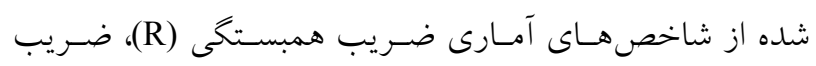
تغييـرات (VAF)، خطـاى مربعـات ميـانخين ريشـه (RMSE)، شاخص بر اكندكى (SI)، خطاى مطلق ميانخين (MAE)، درصـد خطاى مطلق ميانخين (MAPE)، خطاى نسبى مربعات ميـانخين

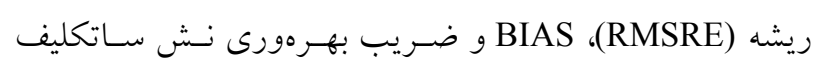
(NSC)

$$
R=\frac{\sum_{i=1}^{n}\left(F_{i}-\bar{F}\right)\left(O_{i}-\bar{O}\right)}{\sqrt{\sum_{i=1}^{n}\left(F_{i}-\bar{F}\right)^{r} \sum_{i=1}^{n}\left(O_{i}-\bar{O}\right)^{r}}}
$$

$\mathrm{VAF}=\left(1-\frac{\operatorname{var}\left(\mathrm{F}_{\mathrm{i}}-\mathrm{O}_{\mathrm{i}}\right)}{\operatorname{var}\left(\mathrm{F}_{\mathrm{i}}\right)}\right) \times 1$ 。

RMSE $=\sqrt{\frac{l}{n} \sum_{i=1}^{n}\left(F_{i}-O_{i}\right)^{r}}$

$\mathrm{SI}=\frac{\mathrm{RMSE}}{\overline{\mathrm{O}}}$

MAE $=\frac{\sum_{\mathrm{i}=1}^{\mathrm{n}}\left|\mathrm{F}_{\mathrm{i}}-\mathrm{O}_{\mathrm{i}}\right|}{\mathrm{n}}$ 
جدول ا. ضرايب نرمالسازى براى شرايط مختلف

\begin{tabular}{|c|c|c|}
\hline $\mathrm{b}$ & $\mathrm{a}$ & ضرايب نرمالسازى \\
\hline-1 & $r$ & نرمال 1 \\
\hline 。 & 1 & نرمال r \\
\hline$\circ / 1$ & $\circ / \Lambda$ & نرمال r \\
\hline $0 / Y$ & $0 / 9$ & نرمال † \\
\hline 。 & 1 & بدون نرمال \\
\hline
\end{tabular}

زيرزمينى در جاه مشاهداتى ناجيز است بنابراين مقادير تراز آب زيرزمينى با استفاده از

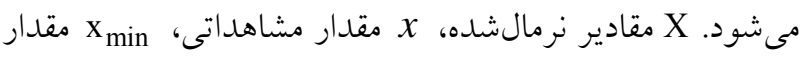

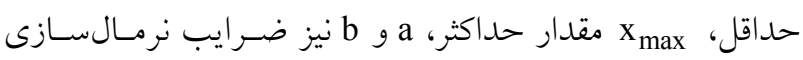
هستند. بهعبارت ديخر، براى اينكه مقادير مشاهداتى بين صفر و

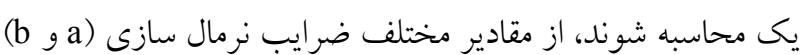
مختلف استفاده مى شود. همشجنين ضرايب نرمالسـازى مختلـف در جدول ( (1) نشان داده شده اسـت. در شـكل هــاى (Y) و (r) مقايسـه مقـادير تـــاز آب يــيشبينسى شـده توســط ضـرايب نرمالسازى مختلف به تصوير كشيده شده است. بر اساس نتايج نرمالسازى، در شرايطى كه ضرايب a و b بهترتيب مساوى r و 1- هستند، دقت مدل سازى به شكل قابل ملاحظــاى افـزايش مىيابد. بهعنوان مثال در حالت تست، مقادير R و RMSE براى

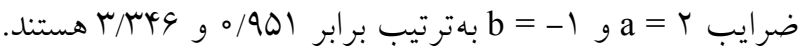

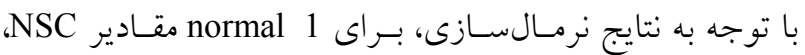

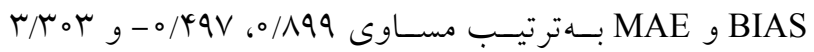

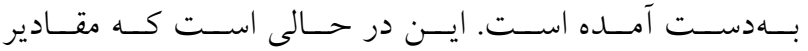

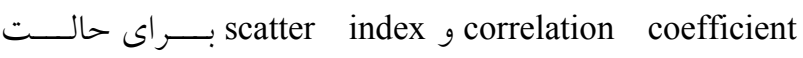

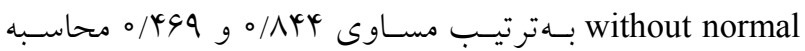
شدهاند. بر اساس نتايج مـدلسـازى، normal داراى بيشـترين 1 دارئ همبستخى با مقادير مشاهداتى است. بنابراين در ادامسه ضـرايب b= ب إى تخمين تغييرات تراز آب زيرزمينى استفاده

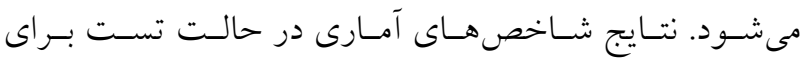
نرمالسازىهاى مختلف در جدول (Y) مرتب شده است.

$$
\begin{aligned}
& \text { MAPE }=\frac{1}{n} \sum_{i=1}^{n}\left(\frac{\left|F_{i}-O_{i}\right|}{O_{i}}\right) \\
& \text { RMSRE }=\sqrt{\frac{1}{n} \sum_{i=1}^{n}\left(\frac{O_{i}-F_{i}}{O_{i}}\right)^{r}} \\
& \text { BIAS }=\frac{1}{n} \sum_{i=1}^{n}\left(F_{i}-O_{i}\right) \\
& N S C=1-\frac{\sum_{i=1}^{n}\left(O_{i}-F_{i}\right)^{r}}{\sum_{i=1}^{n}\left(O_{i}-\bar{O}\right)^{r}}
\end{aligned}
$$

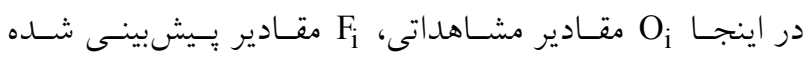

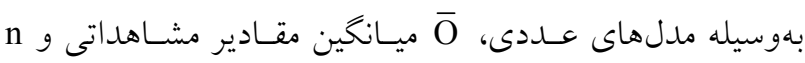
برابر تعداد مقادير مشاهداتى است.

\section{بحث و نتايج}

در ادامه، ابتدا به نرمالسازى نتايج مشاهداتى برداخته مىشود و بهينهترين ضرايب نرمـالسـازى انتخـاب مىشـوند. سـيس بـــ ارزيابى انتحاب خـانو اده موجــ يرداختـهـ مسى شـود و بهتـرين خانواده مو جك شناسايى مىشود. در قسمت بعدى، هشت مدل مختلف براى هر يك از مــلهــاى SAELM و WA-SAELM توسعه داد شده و با تجزيه و تحليل نتايج مدلسازى مـدلهـاى برتر معرفى مىشوند. همجنين توزيع خطاى اين مدلها نيز اجرا

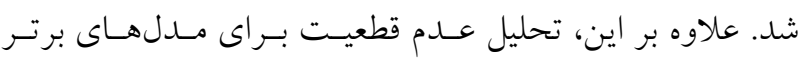
SAELM نرمال سازى با توجه به اينكه اختلاف بين حداقل و حداكثر مقـدار تـــاز آب 

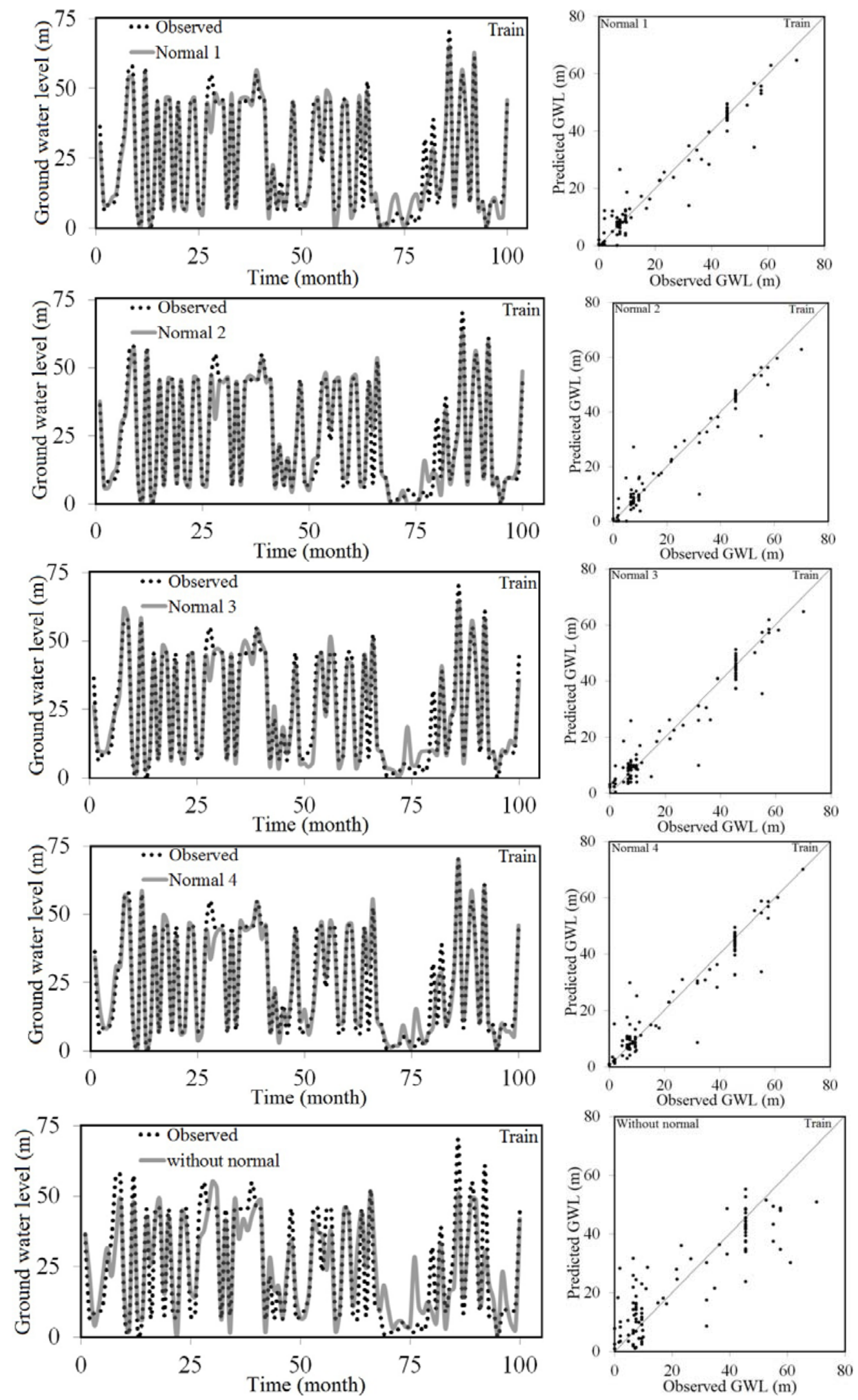

شكل r. مقايسه نتايج نرمالسازى شده با مقادير مشاهداتى براى حالتهاى مختلف در حالت آموزش 

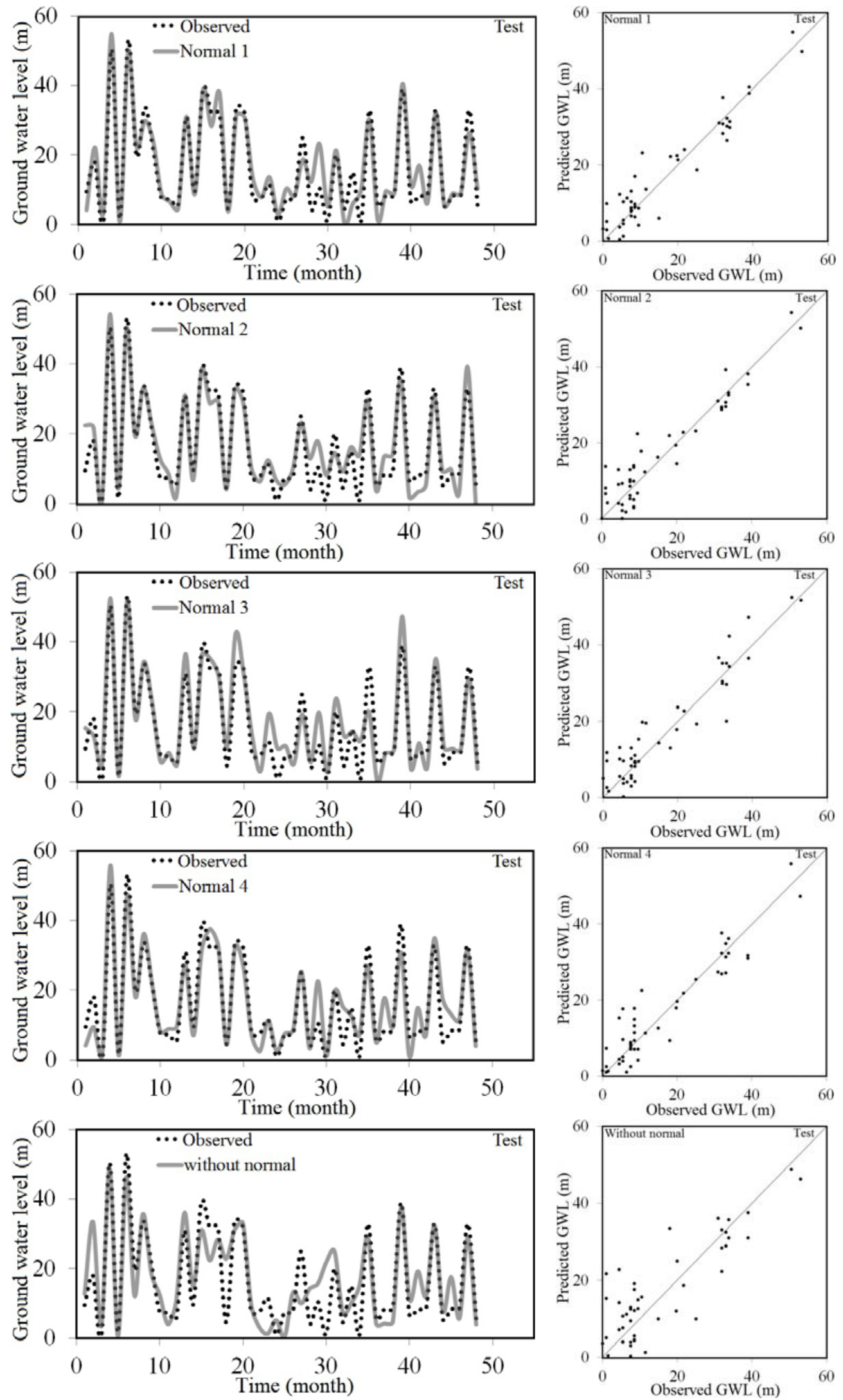

شكل r. مقايسه نتايج نرمالسازى شده با مقادير مشاهداتى براى حالتهاى مختلف در حالت تست 
جدول r. نتايج شاخصهاى آمارى براى نرمالسازىهاى مختف در حالت تست

\begin{tabular}{|c|c|c|c|c|c|c|c|c|c|}
\hline NSC & BIAS & RMSRE & MAPE & MAE & SI & RMSE & VAF & $\mathrm{R}$ & تست \\
\hline $0 / 1999$ & $-0 / 49 V$ & $1 / \Delta+1$ & olgkt & $r / \mu \circ \mu$ & $0 / T G \Lambda$ & F/THG & $q \circ / \mu \wedge$ &.$/ 901$ & نرمال 1 \\
\hline -/MAY & $-0 / 0 \circ 1$ & $r / 4 q q$ & $0 / 990$ & $r / 90 \mathrm{~V}$ & $\circ / T \wedge V$ & $Y / 90 \mathrm{~V}$ & MN/NOY & $0 / 944$ & نرمال r \\
\hline -/AVq & $-1 / 1 \wedge \mu$ & $T / \circ V$ & -NOY & $r / v \circ r$ & $0 / 791$ & Y/AKT & $\Lambda \Lambda / \Delta \wedge V$ & $0 / 94 t$ & نرمال r \\
\hline - NAYD & $0 / 09 r$ & $1 / 194$ & $\circ / \Delta \wedge \vee$ & r/A9D & וTM/ס & س & $\Lambda Q / \circ<q$ & $0 / 9 T Y$ & نرمال † \\
\hline 01994 & $-0 / 94 \mid$ & T/NFT & $1 / 410$ & $9 / 019$ & $0 / 499$ & $V / 090$ & VO/TYG & $0 / N k y$ & بدون نرمال \\
\hline
\end{tabular}
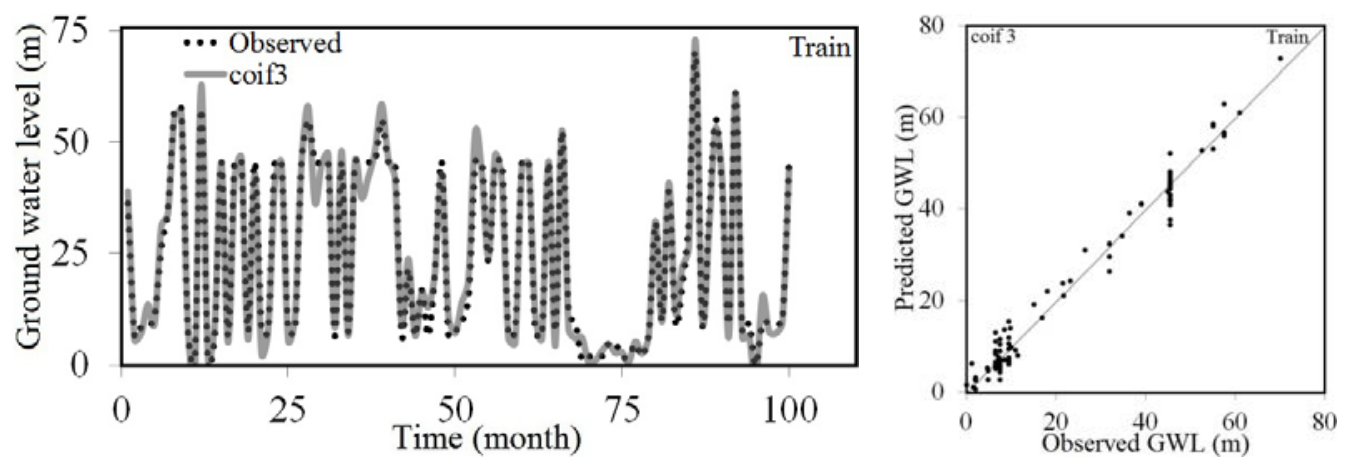

شكل †. مقايسه نتايج mother wavelet selection با مقادير مشاهداتى براى حالت آموزش
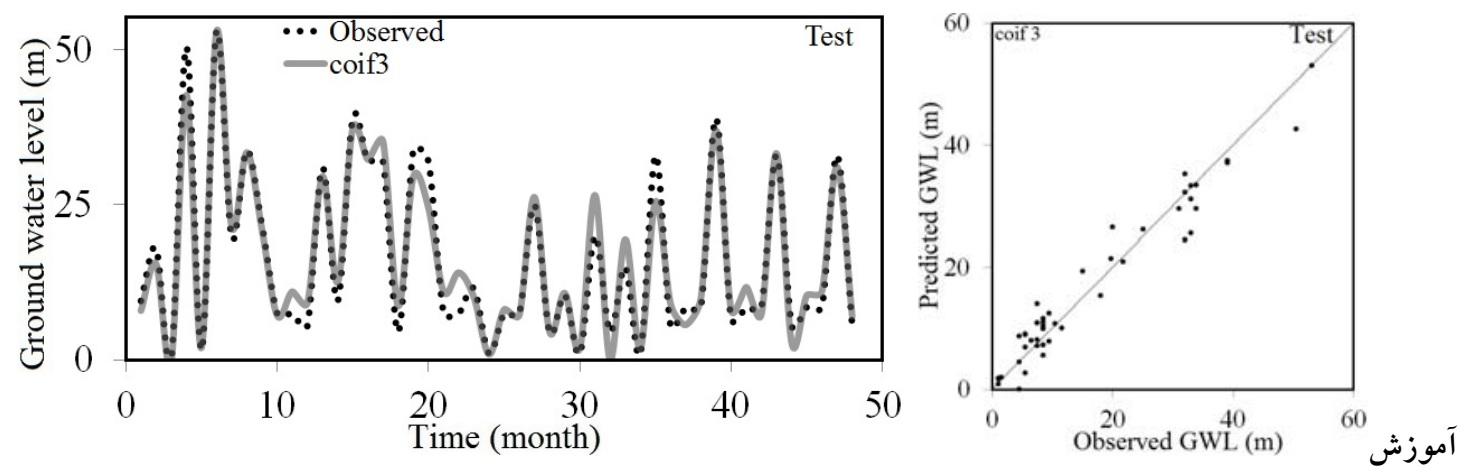

شكل ه. مقايسه نتايج mother wavelet selection با مقادير مشاهداتى براى حالت تست

حالت تست در جدول (r) نشان داده شده است. بهعنوان مثـال،

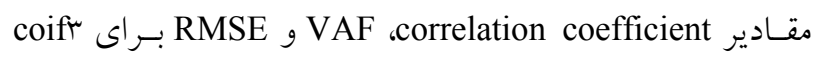

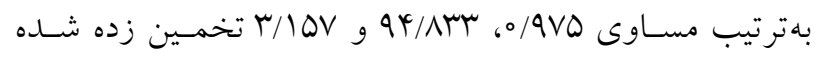

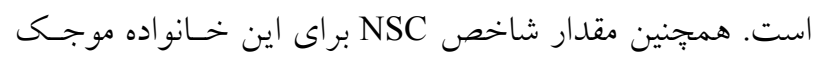

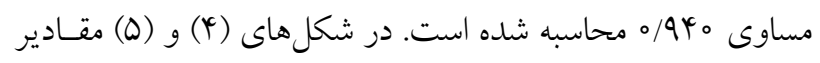

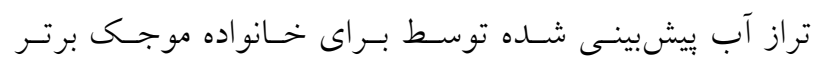
(coifr)

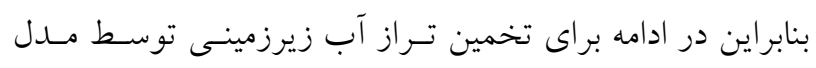

بررسى خانوادههاى موجى

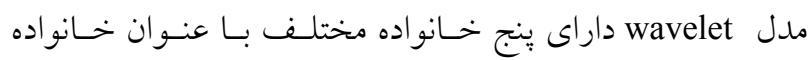

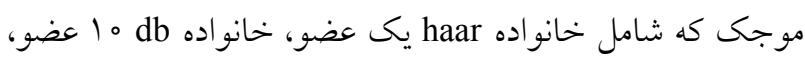

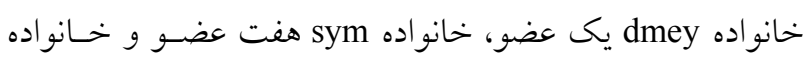
coif

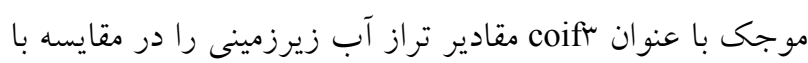

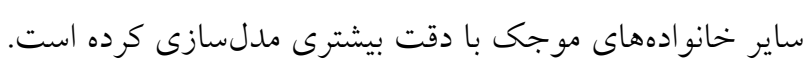

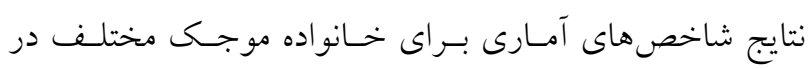


جدول r. نتايج شاخصهاى آمارى براى خانواده موجك مختلف در حالت تست

\begin{tabular}{|c|c|c|c|c|c|c|c|c|c|c|}
\hline NSC & AIC & BIAS & RMSRE & MARE & MAE & SI & RMSE & VAF & $\mathrm{R}$ & خانو اده موجك \\
\hline $0 / 909$ & $V \pi / 101$ & $-\circ / \Gamma \wedge \Delta$ & $\circ / 9 \circ 1$ & 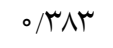 & $r / \circ V V$ & $0 / 790$ & $4 / Y 19$ & Q०/NYr &.$/ 90 Y$ & haar \\
\hline $0 / 194$ & $V Q / G \wedge \Gamma$ & $-0 / 0 V Q$ & T/lVG & $0 / 9 V A$ & r/TVA & $\circ / T V D$ & $Y / Y Q T$ & $19 / 99 \mathrm{~V}$ & $0 / 94 \wedge$ & $\mathrm{db})$ \\
\hline$\circ / 9 Y_{0}$ & VI/9Rr & $-0 / 191$ & $1 / 4 \circ 4$ & $0 / g$ Mr & T/TYV & - TQY & $\varphi / 11 \Lambda$ & $91 / 199$ & $0 / 909$ & $\mathrm{dbr}$ \\
\hline.$/ 914$ & $V T / 991$ & $-0 / 9 \wedge r$ & $\circ / V D Y$ & $0 / 499$ & $r / \mu V r$ & $0 / T 90$ & $Y / Y 10$ & $91 / 049$ &.$/ 90 \mathrm{~V}$ & $\mathrm{dbr}$ \\
\hline.$/ 949$ & $90 / 9 \vee 9$ & $-0 / 910$ & $\circ / \Lambda \Lambda \circ$ & $0 / 409$ & r/1999 & O & $r / 910$ & $Q M / 4 Y \wedge$ &.$/ 991$ & $\mathrm{db}^{\mathrm{c}}$ \\
\hline.$/ 9 k r$ & Gr/AYq & $-0 / 9 \mathrm{VV}$ & O/NIT & - $4 \Delta t r$ & $r / \wedge 9 Y$ & $0 / Y I Y$ & $r / \uparrow \vee q$ & $9 \pi / 944$ & $\circ / 9 V T$ & $\mathrm{db} \omega$ \\
\hline.$/ 940$ & $q \pi / Y q Q$ & $-0 / 490$ & $\circ / 9 V Y$ & $\circ / 4 V Y$ & $r / \Lambda \mid r$ & $0 / Y I T$ & r/sy。 & $9 \pi / 994$ & $\circ / 9 V_{0}$ & $\mathrm{db} \varphi$ \\
\hline $0 / 9 \mu^{4}$ & $90 / 9 \circ 0$ & $-0 / \Lambda \mid r$ & I/OYA & $\circ / 0 \wedge 9$ & $r / M T_{1}$ & O/YTY & T/GTr & $q \mu / 4 \wedge s$ & $0 / 991$ & $\mathrm{db} \vee$ \\
\hline.$/ 9 r v$ & GK/VVY & $-0 / 101$ & О/ArA & $\circ / 4 Y Q$ & $\mathrm{r} / 9 \mathrm{VV}$ & $0 / T / Y$ & $r / \mu V \varphi$ & $Q M / N T$ & $0 / 999$ & $\mathrm{db} \wedge$ \\
\hline.$/ 944$ & $G I / O V Y$ & $-\circ / T \circ \Delta$ & ./90r & $0 / 4 \mid Y$ & $r / 490$ & $\circ / T \circ \Delta$ & & $q 4 / 4 q 1$ & $0 / 9 V Y$ & $\mathrm{db} q$ \\
\hline.$/ 9 \mu \wedge$ & $G Q / 4 \wedge \Lambda$ & $0 / 094$ & $0 / 119$ & - YYTD & $r / \Lambda \circ Y$ & O/YYY & $r / 9 \circ \circ$ & $q \pi / r q \mu$ & $0 / 999$ & $\mathrm{db} / \circ$ \\
\hline - /9TO & $99 / 111$ & $-0 / \mu \mathrm{M}$ & $1 / 409$ & $\circ / \Delta \Delta V$ & T/VQQ & O/TYA & $r / v 01$ & $9 Y / 9 V 9$ &.$/ 994$ & dmey \\
\hline.$/ 9 T V$ & $G V / r q 4$ & $-1 / 094$ & ס & $\circ / N \Lambda \Delta$ & r/9G & ו ו & 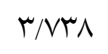 & GMTrT &.$/ 99 \mathrm{~V}$ & symr \\
\hline $0 / 941$ & GY/Ar。 & $-\circ / \Delta \Delta r$ &.$/ 9 V r$ & ONGY & r/gसr & $0 / Y 10$ & $r / \varphi \circ \varphi$ & $q Y / I T V$ & $0 / 9 V 1$ & symr \\
\hline ./9rr & GN/NYA & $-0 / 199$ & $1 / \circ V Q$ & $\circ / 001$ & r/or。 & ס & r/ASI & $91 / 994$ & ./994 & symץ \\
\hline $0 / 901$ & $V 9 / 9 \circ 9$ & -0/4rs &.$/ 991$ &.$/ 494$ & $r / \Delta 1 \circ$ & $0 / Y \wedge \circ$ & r/Drq & $\Lambda 9 / \mu \wedge \Lambda$ &.$/ 900$ & symo \\
\hline.$/ 90 \wedge$ & Or/VQT & $-0 / \mu_{01}$ & $1 / T \circ 9$ & o/fyes & $T / Y Y Y$ & $0 / I V A$ & $r / 119$ & $90 / 910$ & $\circ / 910$ & syms \\
\hline.$/ 94 \wedge$ & $09 / 09 \circ$ & $-\circ / V \circ V$ & o/vIY & $0 / 4 \mid 4$ & r/OQ9 & $0 / 199$ & $\varphi /|\Lambda|$ & $94 / 919$ & $\circ / 9 \vee Q$ & sym $\vee$ \\
\hline ./90r & ON/OYr & $.0 q r$ & $0 / V 90$ & $0 / 410$ & $r / c V r$ & $0 / 190$ & $r / \circ \wedge r$ & $90 / .9 V$ & - /9VG & $\operatorname{sym} \wedge$ \\
\hline $0 / 919$ & $V Y / M N I$ & $-0 / 9 \mu V$ & $1 / 040$ & $\circ / \uparrow \wedge 。$ & $r / 4 \circ q$ & $0 / T \& V$ & سחתוץ & $9 \circ / 40 \circ$ &.$/ 901$ & coif $\mid$ \\
\hline.$/ 949$ & $G \Lambda / 4 G \Lambda$ & $-0 / 0 \wedge k$ & $1 / r q 4$ & - & $r / 99 V$ & G/TM & T/ANI & $Q T / T V Y$ &.$/ 994$ & coift \\
\hline.$/ 940$ & $\Delta 9 / 1 \wedge \Lambda$ & $-\circ / I V Q$ & $\circ / 4 \circ r$ & $0 / T N 1$ & $r / T G V$ & $0 / 190$ & $r / I Q V$ & سז/A & $0 / 9 V 1$ & coifr \\
\hline $0 / 949$ & $\Delta Q / \Lambda V \Delta$ & $-0 / 9 \wedge \circ$ & $1 / 0 V 0$ & $0 / 4 \wedge 1$ & $r / 9 \circ 4$ &.$/ 191$ & $r / r \circ \mu$ & $q 4 / 9 \circ V$ & $\circ / 9 \vee \Delta$ & coifte \\
\hline.$/ 940$ & $91 / 0 \wedge k$ & -o/gkt & $\circ / \Delta V_{0}$ & $0 / M Y \Lambda$ & $r / 099$ & $0 / Y \circ Y$ & $\Gamma / Y \wedge \Delta$ & $94 / 909$ & $\circ / 9 V \pi$ & coifd \\
\hline
\end{tabular}

در ميان كليه مدلهاى SAELM مـــ SAELM مقــادير تـراز آب زيرزمينى را با دقت بيشترى بيشبينى كرده است. در حالت

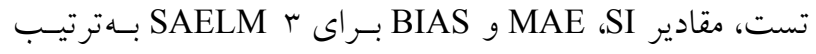

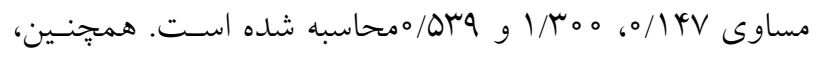
مقدار NSC-Sutcliffe efficiency coefficient بـراى ايـن مــل

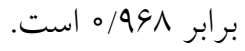
عـلاوه بــر ايـن، در شـكل (9) نحــوه مـــلسـازى تـراز
از Wavelet-SAELM

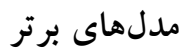

همان كونه كه بيان شــ هشـت مـــل متمــايز بــراى هـر يـك از مدلهاى SAELM و WA-SAELM توسعه داده شـده اسـت و در ادامه به معرفى مــلهــاى برتـر SAELM و WA-SAELM يرداخته مىشود. در ابتدا مدلهاى SAELM ارزيـابى مىشـوند. 
جدول Y. نتايج شاخصهاى آمارى براى مدلهاى مختلف SAELM در حالت تست

\begin{tabular}{|c|c|c|c|c|c|c|c|c|c|}
\hline $\mathrm{NSC}$ & BIAS & RMSRE & MARE & MAE & SI & RMSE & VAF & $\mathrm{R}$ & \\
\hline$-Y / 0 \circ V$ & $-1 / 019$ & $4 / Y 99$ & I/VYr & $10 / V K^{\prime}$ & O/AMI & $\mid r / 4 V \pi$ & G/AYO & O/MTI & SAELM I \\
\hline o/VA & $-0 / \wedge \mu q$ & 1/0 & $0 / \mu_{1}$ & T/YQT & $\circ / \mu V Y^{c}$ & $9 / 091$ & $11 / 794$ & $\circ / 9 \circ Y$ & SAELM r \\
\hline.$/ 991$ & -/orq &.$/ 910$ & - TQA & $1 / \mu \circ \circ$ &.$/ 14 V$ & $r / \Gamma \wedge 。$ & $9 V / T \circ q$ & $0 / 919$ & SAELM \\
\hline.$/ 9 \mu_{0}$ & $\circ / \mu \circ r$ & $1 / 094$ & سחצא & T/MGT & $0 / Y I V$ & $r / 0 \circ q$ & $q M / G 4 V$ & $0 / 991$ & SAELM ${ }^{\complement}$ \\
\hline ./ard & $-0 / I V Y$ & $1 / \pi \Delta \circ$ & سMט/. & $r / \Delta 0^{\circ}$ & O/YYO & $r / \Delta \Delta \Lambda$ & $9 r / 4+4$ &.$/ 991$ & SAELM $\triangle$ \\
\hline.$/ 941$ & $-0 / \mu q 4$ & l/var & .1901 & T/VGA & - TYO & r/qrq & $94 / 191$ & $0 / 999$ & SAELM 9 \\
\hline$\circ / \Lambda \Lambda 0$ & $-0 /\left.4\right|_{1}$ & $1 / 0 V I$ & . & $r / \Delta \Delta r$ & $0 / r q 1$ & $Y / V Y I$ & $M / D 1 \circ$ & o/9KT & SAELM $\vee$ \\
\hline $0 / 1999$ & $-0 / 49 V$ & $1 / D Y 1$ & OIGYY & $r / \mu \circ \mu$ & $0 / T G \Lambda$ & Y/MYG & $q \circ / \mu \circ \wedge$ & $0 / 901$ & SAELM $\wedge$ \\
\hline
\end{tabular}
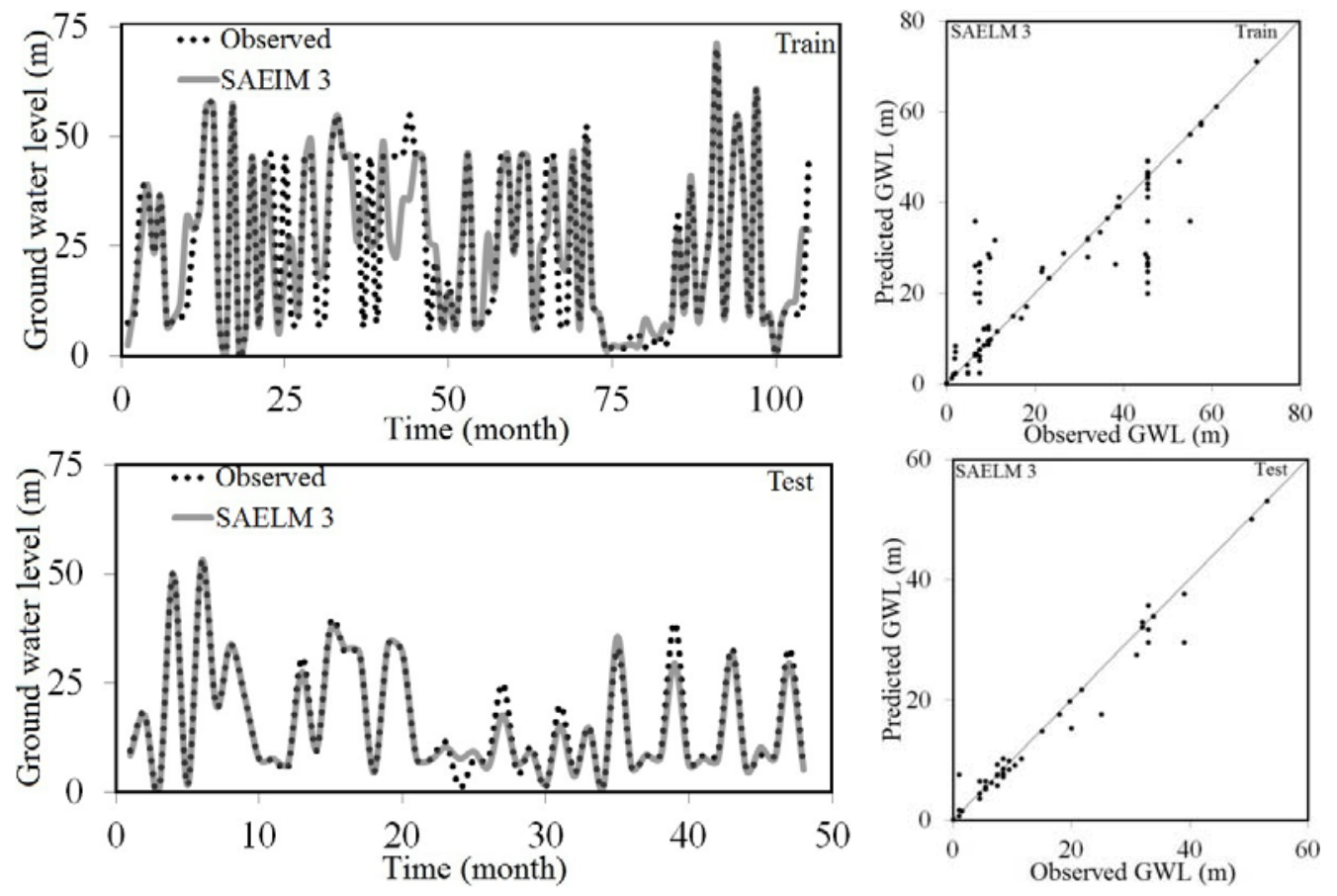

شكل و. مقايسه نتايج rSAELM با مقادير مشاهداتى براى حالتهاى آموزش و تست

مقادير RAE و MSC براى اين مدل بهترتيب برابـر 1990ه،

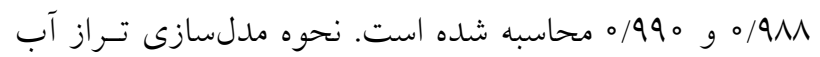
زيرزمينى در شرايط آموزش و تست توسط اين مــل در شكل نشـان داده شـده اسـت. بــر اسـاس تجزيسهو تحليـل نتـايج مدلسازىهاى عددى، در بـين كليـه مـدلهـاى معرفى شـده، WA-SAELM ب بهعنو ان مدل برتر معرفى مىشـود. همجنــين در جدول (ه) نتايج شاخص هاى آمارى محاسبه شده بـراى مـدلهـاى
آب زيرزمينسى مــدل r SAELM در هــر دو حالـت آمـوزش و

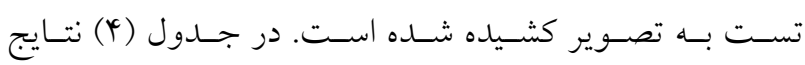
شاخصهاى آمارى براى مدلهاى مختلف SAELM در حالـت تست مرتب شده است. همجنين در ادامه به بررسى مــدل برتـر يرداخته مىشود. با توجـهـ بـه نتـايج مـدلهـاى WA-SAELM

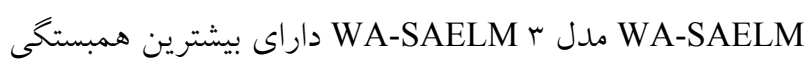
و كمترين مقدار خطا اسـت. بـهـعنـوان مثــال، مقــادير همجنــين 

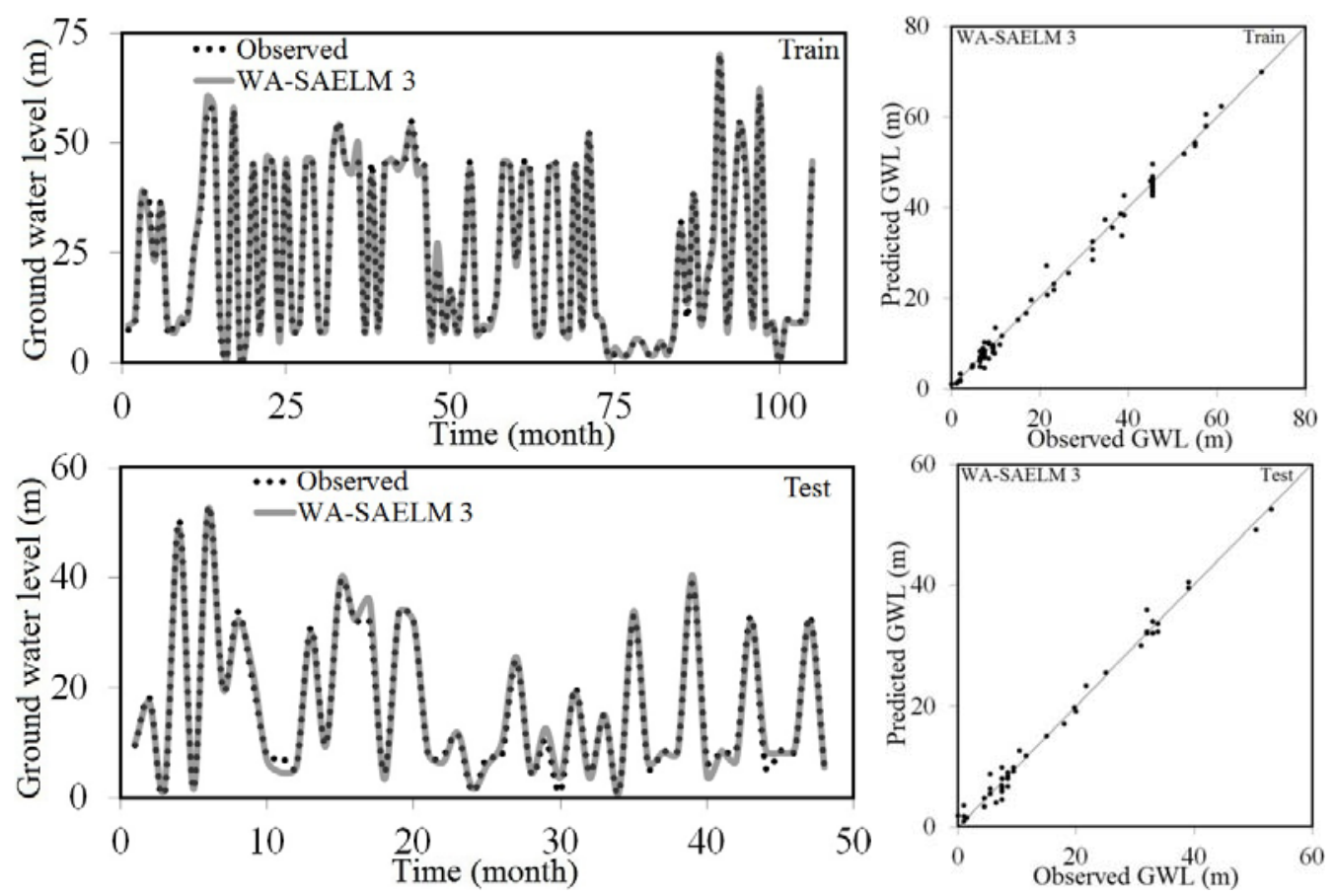

شكل V. مقايسه نتايج rWA-SAELM با مقادير مشاهداتى براى حالتهاى آموزش و تست

جدول ه. نتايج شاخصهاى آمارى براى مدلهاى مختلف WA-SAELM در حالت تست

\begin{tabular}{|c|c|c|c|c|c|c|c|c|c|}
\hline $\mathrm{NSC}$ & BIAS & RMSRE & MARE & MAE & SI & RMSE & VAF & $\mathrm{R}$ & \\
\hline$\circ / \wedge 01$ & $\circ / \mu 1 \wedge$ & $\circ / N{ }^{4}$ & $\circ / 4 \circ V$ & $r / 901$ & . & $\Delta / \Lambda \wedge \circ$ & $\Lambda Y / \circ \wedge l$ & $\circ / 9 \circ V$ & WA-SAELM I \\
\hline$\circ / 9 \circ V$ & $0 / 499$ & $|/ D Y|$ & $0 / 099$ & $\mu /$ TGV & $\circ / Y G V$ & Y/TYO & $Q \circ / \mu Y V$ & -/90r & WA-SAELM $r$ \\
\hline $0 / 99 \circ$ & $-0 / 090$ & $0 / 440$ & $\circ / \mathrm{VA}$ & $0 / 9 \wedge 1$ & $\circ / \circ \wedge \uparrow$ & $1 / r \Delta V$ & $99 / 044$ & $0 / 990$ & WA-SAELM \\
\hline.$/ 949$ & -o/VYq & $\circ / \Delta \vee \wedge$ & $\circ / \mu y \circ$ & $r / \Delta \vee Q$ & $0 / Y_{01}$ & r/TGY & $94 / N{ }^{4}$ & $\circ / 9 \vee Q$ & WA-SAELM ${ }^{*}$ \\
\hline.$/ 909$ & $-0 / 091$ & o/4G & $\circ / T \wedge V$ & $r / r q \circ$ & $\circ / \mathrm{VV}$ & $r / A V Y$ & $9 \Delta / V \circ V$ & $\circ / 9 \vee 9$ & WA-SAELM $ه$ \\
\hline$\circ / 900$ & $-0 / 1 \wedge r$ & $\circ / V Y \circ$ & $\circ / 4 \circ r$ & $r / 001$ & $0 / 119$ & $r / 090$ & $9 Q / 1 \mu_{Y}$ &.$/ 9 \mathrm{VV}$ & WA-SAELM 9 \\
\hline.$/ 9 Y 4$ & $-0 / 911$ & $\circ / \mathrm{VY}$ & $0 / 419$ & $r / 901$ & $0 / \pi \mu_{0}$ & r/VY。 & $9 r / 999$ &.$/ 990$ & WA-SAELM $\vee$ \\
\hline.$/ 940$ & $-\circ / I V Q$ & $\circ / 4 \circ r$ & $0 / Y \wedge 1$ & r/TGV &.$/ 190$ & $r / l Q V$ & س & $\circ / 9 \vee \Delta$ & WA-SAELM $\wedge$ \\
\hline
\end{tabular}

توجه به نتايج توزيع خطا، در حدود سب مقادير آب زيـرزمينى بيشبينى شده توسط r SAELM خطايى بيشتر از م ا درصد بـه خود اختصاص دادهاند. در حالت تست، مـدل r WA-SAELM بيش از نيمى از مقادير شبيهسازى شده را با خطايى كمتر از بنج درصد محاسبه كرده است و يك سوم تراز آب زيرزمينى تخمين زده شده خطايى بيشتر از ه ا درصد دارند. لازم بهذكر است كـه له

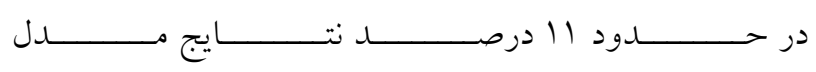
WA-SAELMr
مختلف WA-SAELM نشان داده شده است. همجِنين در ادامه بـه (SAELM r and WA- نحوه توزيع خطا بـراى مـدلهـاى برتـر SAELM r) خطا براى مدلهاى برتر در هر دو حالت آموزش و تسـت نشـان داده شده است. بهعنوان مثال در حالت آموزش، مدل SAELM r تقريبا VV درصد نتايج مشاهداتى را بـا خطـاى كمتـر از يـنج درصد تخمين مىزند. همجنين در حدود ه ا درصد نتسايج ايسن مدل داراى خطايى بين ه تا ه ا درصد دارند. علاوه بــر ايسن بـا 


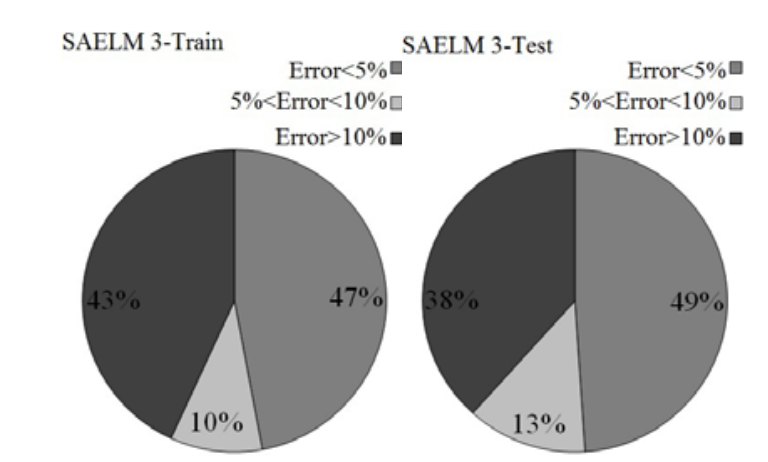

شكل ^. توزيع خطا براى مدل r SAELM در حالتهاى آموزش و تست

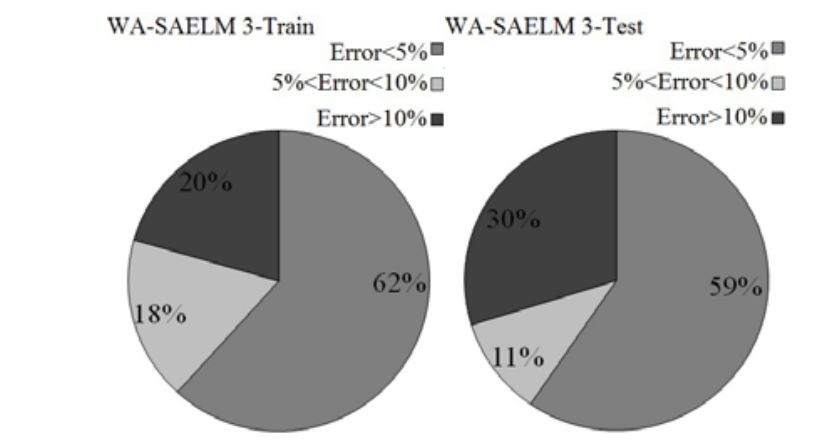

شكل 9. توزيع خطا براى مدل r WA-SAELM در حالتهاى آموزش و تست

جدول و. نتايج تحليل عدم قطعيت براى مدلهاى r SAELM و r WA-SAELM در حالت تست

\begin{tabular}{|c|c|c|c|c|c|c|}
\hline حدود اعتماد 90 درصد & يهناى باند عدم قطعيت & $\mathrm{S}_{\mathrm{e}}$ & انحراف استاندارد & ميانخين خطاى بيشبينى & تعداد نمونهها & مدلها \\
\hline $1 / K K V,-0 / I K T$ & $. / 990 \pm$ & $0 / \mu Y \Delta$ & T/MGG & - /QDY & \&V & SAELMr \\
\hline $0 / M V V,-0 / 4 Y I$ & $\circ / \mu 99 \pm$ & $0 / 191$ & $1 / \pi \Delta 9$ & -O/OYT & \&V & WA-SAELM r \\
\hline
\end{tabular}

مقدار e نشاندهنده عملكرد كمتر از مقدار واقعى بـودن مــل

عددى است. در مقابل مثبت بودن e به معناى عملكرد بيشتر از

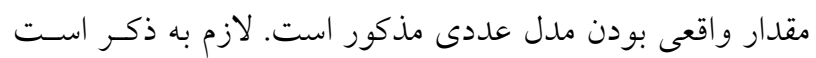

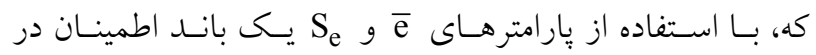
اطر اف مقادير بيشبينى از يك خطا توسط روش ويلسون توليد مىشود. در ادامه با استفاده از I/94S به ه9 درصد باند اطمينان مىشود. در جدول (9) نيز بارامترهاى بــهدسـت آمــده بــراى تحليـل عــدم قطعيـت مــدلهـــاى SAELM « and WA-SAELM است. با توجه به تحليل عدم قطعيـت، مـدل r SAELM داراى

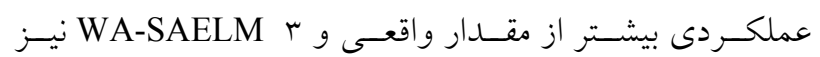
عملكردى كمتر از مقدار واقعى هستند. علاوه بر اين ه9 درصـد
تحليل عدم قطعيت

SAELM r and مر اين قسمت تحليل عدم قطعيت مــلهــاى

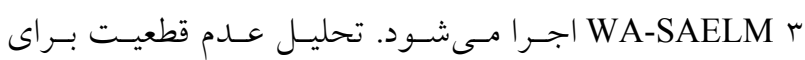
ارزيابى خطاى بيشبينىشده توسط مــلـهـاى عـددى اسـتفاده

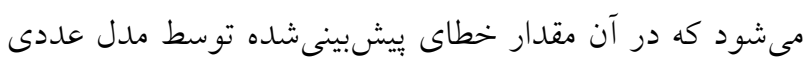
به (e)

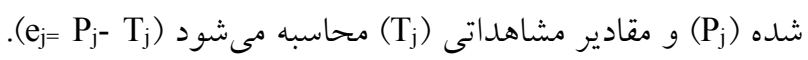

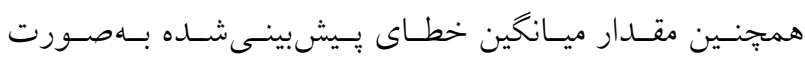

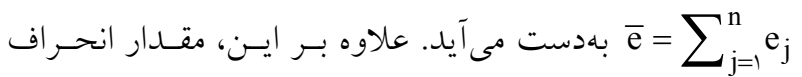

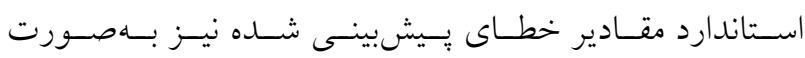
تعريف مسى شـود. منفسى بــودن $S_{e}=\sqrt{\sum_{j=1}^{n}\left(e_{j}-\bar{e}\right)^{r} / n-1}$ 


$$
\begin{aligned}
& \text { coifr بهنوان عضو برتر خانو ادههاى موجـك معرفـى شــ كـه } \\
& \text { دقت مدل ماشين آموزش نيرومند خود تطبيقى را بهبود بخشيد. } \\
& \text { سيس مدل هاى برتر براى تخمــين تـراز آب زيرزمينـى معرفـى } \\
& \text { شدند. تجزيهوتحليل نتايج مدلسازى نشـان داد كـهـ مـدلهـاى } \\
& \text { WA-SAELM } \\
& \text { هدف را با دقت بيشترى مقايسه كرد. بهـنوان مثــال بـراى مــل }
\end{aligned}
$$

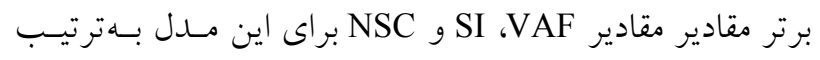

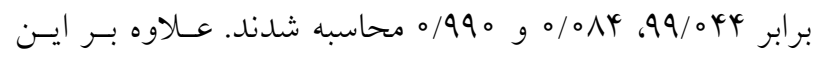

$$
\begin{aligned}
& \text { نتايج تحليل علدم قطعيت نشان داد كه مدل برتر WA-SAELM } \\
& \text { داراى عملكردى كمتر از مقدار واقعى است. لازم بـهذكر اسـت } \\
& \text { كه عرضى باند علم قطعيت براى مدل برتر بين مثبـت وهץ/ه و } \\
& \text { منفى 99/\% بهدست آملد. }
\end{aligned}
$$

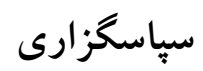

$$
\begin{aligned}
& \text { يزووهش حاضر با حمايـت مـالى دانشـعاه آزاد اسـلامى واحـد } \\
& \text { كرمانشاه انجام شده است. بنابراين نويسندگان اين مقاله مراتـب } \\
& \text { قدردانى و تشكر خود را از دانشگاه آزاد اسلامى واحد كرمانشاه } \\
& \text { براى حمايت مالى از اين يزوهش ابراز ميدارند. }
\end{aligned}
$$

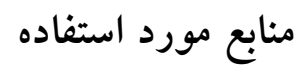

1. Barzegar, R., E. Fijani, A. A. Moghaddam and E. Tziritis. 2017. Forecasting of groundwater level fluctuations using ensemble hybrid multi-wavelet neural network-based models. Science of the Total Environment 599: 20-31.

2. Cao, J., Z. Lin and G. B. Huang. 2012. Self-adaptive evolutionary extreme learning machine. Neural Processing Letters 36(3): 285-305.

3. Huang, G. B., Q. Y. Zhu and C. K. Siew. 2004. Extreme learning machine: A new learning scheme of feedforward neural networks. In: Proceedings of the International Joint Conference on Neural Networks, Budapest, Hungary, 2 : 985-990.

4. Huang, G. B., Q. Y. Zhu and C. K. Siew. 2006. Extreme learning machine: theory and applications. Neurocomputing 70(1): 489-501.

5. Khaki, M., I. Yusoff and N. Islami. 2015. Simulation of groundwater level through artificial intelligence system. Environmental Earth Sciences 73(12): 8357-8367.

6. Lerner D. N., A. S. Issar and I. Simmers. 1990. Groundwater Recharge: A Guide to Understanding and Estimating Natural Recharge. Report 8. Int. Assoc. Hydrogeol., Kenilworth, UK.

7. Makungo, R and J. O. Odiyo. 2017. Estimating groundwater levels using system identification models in Nzhelele and Luvuvhu areas, Limpopo Province, South Africa. Physics and Chemistry of the Earth, Parts A/B/C 100: 44-50.

8. Malekzadeh, M., S. Kardar, K. Saeb, S. Shabanlou and L. Taghavi. 2019. A novel approach for prediction of monthly ground water level using a hybrid wavelet and non-tuned self-adaptive machine learning model. Water Resources Management 33(4): 1609-1628.

9. Misiti M., Y. Misiti, G. Oppenheim and J. M. Poggi. 1996. Wavelet Toolbox for Use with Matlab. The Mathworks, Inc.: Natick, Massachusetts, USA.

10. Sahoo, S. and M. K. Jha. 2013. Groundwater-level prediction using multiple linear regression and artificial neural 
network techniques: a comparative assessment. Hydrogeology Journal 21(8): 1865-1887.

11. Silhavy, R., P. Silhavy and Z. Prokopova. 2017. Analysis and selection of a regression model for the use case points method using a stepwise approach. Journal of systems and Software 125: 1-14.

12. Storn, R and K. Price. 1997. Differential evolution-a simple and efficient heuristic for global optimization over continuous spaces. Journal of Global Optimization 11(4): 341-359.

13. Suryanarayana, C., C. Sudheer, V. Mahammood and B. K. Panigrahi. 2014. An integrated wavelet-support vector machine for groundwater level prediction in Visakhapatnam, India. Neurocomputing, 145: 324-335.

14. Yoon, H., Y. Hyun, K. Ha, K. K. Lee and G. B. Kim. 2016. A method to improve the stability and accuracy of ANN-and SVM-based time series models for long-term groundwater level predictions. Computers \& Geosciences 90: $144-155$. 


\title{
Prediction of Groundwater Level Changes Using Hybrid Wavelet Self- Adaptive Extreme Learning Machine Model- Observation Well of Sarab Qanbar, Kermanshah
}

\author{
F. Yosefvand ${ }^{*}$ and S. Shabanlou ${ }^{1}$
}

(Received: November 25-2018 ; Accepted: May 21-2019)

\begin{abstract}
In this study, the groundwater level (GWL) of the Sarab Qanbar region located in the south of Kermanshah, Iran, was estimated using the Wavelet- Self- Adaptive Extreme Learning Machine (WA- SAELM) model. An artificial intelligence method called "Self- Adaptive Extreme Learning Machine" and the "Wavelet transform" method were implemented for developing the numerical model. First, by using the autocorrelation function (ACF), the partial autocorrelation function (PACF) and the effective lags in estimating GWL, eight distinctive SAELM and WA- SAELM models were developed. Later, the values of the observational well were normalized for estimating GWL. Next, the most optimized mother wavelet was chosen for the modeling. By evaluating the results of SAELM and WA- SAELM, it was concluded that the WA- SAELM models could estimate the values of the objective function with higher accuracy. Then, the superior model was introduced, showing that it could be very accurate in forecasting the GWL. In the test mode, for example, the values of $R$ (correlation coefficient), Main absolute error (MAE) and the NSC- Sutcliffe efficiency coefficient (NSC) for the superior model were calculated to be $0.995,0.988$ and 0.990 , respectively. Furthermore, an uncertainty analysis was conducted for the numerical models, proving that the superior model had an underestimated performance.
\end{abstract}

Keywords: Groundwater level, Self- Adaptive Extreme Learning Machine (SAELM), Uncertainty analysis, Wavelet transform

1. Department of Water Engineering, Kermanshah Branch, Islamic Azad University, Kermanshah, Iran.

*: Corresponding author: fariborzyosefvand@gmail.com 